\title{
Article \\ Online Pre-Treatment of Thermomechanical Pulp with Emulsified Maleated Polypropylene for Processing of Extruded Thermoplastic Composites
}

\author{
Arne Schirp *(1) and Claudia Schirp (D) \\ Fraunhofer-Institute for Wood Research WKI, 38108 Braunschweig, Germany; claudia.schirp@wki.fraunhofer.de \\ * Correspondence: arne.schirp@wki.fraunhofer.de
}

Citation: Schirp, A.; Schirp, C.

Online Pre-Treatment of

Thermomechanical Pulp with

Emulsified Maleated Polypropylene for Processing of Extruded Thermoplastic Composites. Fibers 2021, 9, 17. https://doi.org/ 10.3390/fib9030017

Academic Editor: Andreas Krause

Received: 31 January 2021

Accepted: 23 February 2021

Published: 3 March 2021

Publisher's Note: MDPI stays neutral with regard to jurisdictional claims in published maps and institutional affiliations.

Copyright: (c) 2021 by the authors. Licensee MDPI, Basel, Switzerland. This article is an open access article distributed under the terms and conditions of the Creative Commons Attribution (CC BY) license (https:/ / creativecommons.org/licenses/by/ $4.0 /)$.
Abstract: The effectiveness of maleated polypropylene (MAPP) in emulsified form for the pretreatment of thermo-mechanical pulp (TMP) before extrusion with polypropylene fibres was evaluated. MAPP in pellet form, which was applied during the compounding step, served as a benchmark. In addition, commercial softwood flour was included as a reference. The influence of the temperature during the defibration process and the presence or absence of the coupling agent on composite performance were evaluated. Composites were processed with a high wood content of 70 wt.\%, which is common for extruded profiles. It was found that TMP based on Robinia (Robinia pseudoacacia L.) conferred higher strength properties to the composites compared to TMP based on Scots pine (Pinus sylvestris L.), which was attributed to the higher length/diameter ratio of fibres in Robinia. However, under the conditions of this study, strength properties were superior and water uptake and swelling were reduced when wood flour was used instead of TMP. On the other hand, in many formulations, larger improvements in flexural and tensile strength due to MAPP were found for the TMP-based composites compared to the wood flour-based composites. This could be due to the larger surface/volume ratio for TMP compared to wood flour and more efficient stress transfer from fibres to the matrix. Results from X-ray photoelectron spectroscopy (XPS) showed that TMP surfaces were more hydrophobic than wood flour due to coverage with lignin, which reduced the effectiveness of MAPP. Esterification between the emulsified MAPP and fibre surfaces was determined using Fourier-Transform Infrared (FTIR) spectroscopy, but some non-activated maleic anhydride remained. Under the conditions of this study, MAPP added during compounding provided better performance compared to MAPP which included a non-ionic emulsifier and which was added during the refining process. Lower temperature $\left(150^{\circ} \mathrm{C}\right)$ during defibration was shown to be beneficial for the strength properties of composites compared to high temperature $\left(180{ }^{\circ} \mathrm{C}\right)$ when MAPP was included in the formulations.

Keywords: wood-plastic composites; maleic anhydride modified polypropylene (MAPP); coupling agent; emulsion; mechanical properties; water uptake; ATR-FTIR spectroscopy; X-ray photoelectron spectroscopy (XPS)

\section{Introduction}

There has been continued interest in the use of wood fibres as opposed to wood flour in the production of wood-plastic composites (WPC), especially for the development of new applications. Wood fibres can be produced by thermomechanical pulping, which is the common process to manufacture fibres for medium-density fibreboard (MDF), or by chemical pulping methods such as Kraft pulping. The main difference in the pulping processes is the target to either preserve or dissolve certain wood components, predominantly lignin, which bonds the fibres together. In thermomechanical pulping, most of the lignin remains, whereas for papermaking, lignin is removed to obtain strong inter-fibre bonding. A commercial product in which cellulose fibres are used is "Fibromer" from the company Mondi. The fibres are combined with polypropylene (PP). The aspect ratio of 
a bleached Kraft pulp fibre is about 100, which offers a high reinforcement and weight savings potential. While the density of glass-fibre reinforced PP is $2.5 \mathrm{~g} / \mathrm{cm}^{3}$, the density of Kraft-fibre reinforced PP is only $1.5 \mathrm{~g} / \mathrm{cm}^{3}$. In addition, colouration is easier to achieve with white, lignin-free cellulose fibres. Cellulose fibre-reinforced PP compounds are also offered by the company UPM (Finland), in this case with 20-50\% filler level and mainly targeted at injection-moulding ("UPM Formi"). Sonae Industria (Portugal) supplies their "Woodforce" as lignocellulosic feedstock for compounding companies [1]. It is based on small dice made from thin MDF panels produced in a commercial MDF plant. Warnes et al. [2] reported that PP reinforced with MDF fibre can achieve comparable strength and stiffness to a commercial flax-reinforced PP and glass fibre-reinforced PP if a higher fibre loading is used. Thermo-mechanical pulp (TMP) is particularly interesting for WPC because such fibres are affordable, of consistent quality and widely available. Another advantage is that during the production process, additives may be directly applied to the fibres, and the fibres are subsequently dried in a continuous process.

As either filler or reinforcement for thermoplastics, mechanical pulp [3,4], thermomechanical pulp [2,5-9], and chemo-thermomechanical pulp (CTMP) [10-16] have been used in scientific investigations. Steam-exploded fibres have also been used in combination with thermoplastics. Renneckar et al. [17] performed a co-steam-explosion process of wood chips with polyolefin to create a fibre with modified sorption properties. On an industrial scale, mostly wood flour is used because, due to low bulk density, pulp is difficult to feed in compounders. Mertens et al. [18] developed a process of simultaneous defibration and compounding employing the refiner technology to overcome the difficulty in feeding TMP into extruders. The process shall be used as an alternative to conventional compounding processes. Mertens et al. [19] also provided a recent review of the utilization of TMP in WPC.

Alternatively, fibres may be pelletized prior to compounding or extrusion. Nygård et al. [20] used fibres from thermo-mechanical and chemo-thermo-mechanical pulping processes, which were pelletized in a Kahl flat die pelletising press. The pellets were then processed using a co-rotating compounder and injection-moulded. Details regarding the refining process were not provided. Peltola et al. [21,22] also used a pelletization process for various wood fibres and compounding with PP and polylactic acid (PLA) followed by injectionmoulding. Wood fibres in these studies were bleached softwood and hardwood Kraft pulps and thermomechanical (peroxide-bleached) pulp. Better reinforcement was achieved with pulp compared to wood flour [22]. TMP fibres provided the best performance in PLA composites.

PLA in combination with TMP was also the subject of a study by Solala et al. [23]. In this study, unbleached spruce TMP was used, which was processed at various defibration temperatures from $130{ }^{\circ} \mathrm{C}$ to $170^{\circ} \mathrm{C}$. As in the investigations by Peltola, injection-moulding was the processing technique. Maximum fibre content in the composites was $20 \mathrm{wt} . \%$. It was concluded that the more hydrophobic high-temperature TMP was evenly dispersed in the PLA matrix, whereas the low-temperature TMP remained partly as visible fibre bundles. However, high-temperature TMP was more severely damaged during extrusion. Filgueira et al. [24] performed enzymatic modification of TMP and used the material in bio-based filaments for 3D-printing with PLA as a polymer matrix. TMP was treated via laccase-assisted grafting of octyl or lauryl gallate onto the fibre surfaces. The modified fibres showed improved hydrophobic properties. Filaments reinforced with octyl gallatetreated TMP exhibited the lowest water absorption and the best interfacial adhesion with the PLA matrix.

Guo et al. [25] used long fibres from nine different wood species as well as hemp and flax fibres, which were all processed using a refiner; however, refining conditions were not reported. They found that the long fibres did not provide significant reinforcement when compared to wood flour-filled WPC. Long fibres were found to be severely degraded by processing, while the wood flour morphology was only slightly changed. 
Thumm and Dickson [8] reported that fibre length only had an influence when it dropped below a critical length. This critical length was found to be consistent with model calculations, which determined the critical fibre length for radiata pine fibres at $0.8 \mu \mathrm{m}$.

One of the key issues with wood and natural fibre composites is to achieve good bonding between the lignocellulose and thermoplastic. In industrial processing technologies, maleated thermoplastics (maleic anhydride-modified polypropylene and polyethylene; MAPP and MAPE) are mostly used for the bonding of wood and polyolefins. They represent the most important coupling agents for wood-plastic composites (WPC) due to their effectiveness, applicability and affordability [26,27]. Usually, they are added in WPC formulations in concentrations between 1\% and 3\%. Maleic anhydride grafted on PP is believed to form covalent ester linkages and hydrogen bonds when reacting with hydroxyl groups at the cellulose interface [28]. This leads to a reduction in WPC water uptake [29] and higher flexural strength compared to uncoupled formulations [5,30-32]. However, with too high concentrations of MAPP in the composite, the strength improvement of WPC may be neutralized or even reversed. The reaction between the MAPP and the polymer matrix is achieved via polymer chain entanglement during heating, which occurs in the compounding step.

Various factors influence the effectiveness of the coupling agent, among them graft content, molecular weight, acid number, applied concentration, wood species and natural fibre type, fibre processing, and composite processing. Specht [33] determined that the application of high-molecular MAPP with low graft content resulted in the highest composite strength and lowest creep properties, whereas low-molecular MAPP with high graft content displayed the lowest water uptake and improved processability. Maleated thermoplastics are usually applied as granules or powder during compounding. In addition, liquid emulsions of maleated thermoplastics are available. However, little information is available with regard to their effectiveness in WPC compared to solid forms of MAPP or MAPE with the same characteristics, i.e., identical anhydride content and molecular weight. The emulsified form provides the advantage that the coupling agent may be added directly onto the fibres prior to compounding, resulting in improved distribution and coupling efficiency. Krzysik and Youngquist [34] used an anionic MAPP emulsion for the bonding of flat-pressed panels made with Western hemlock refiner fibres and polypropylene fibres. Under the conditions of their study, the MAPP emulsion significantly increased bending and tensile strength and moduli, as well as dynamic modulus, compared to uncoupled formulations. Different results were reported by Nechwatal et al. [35], who did not determine any differences in performance when either MAPP in dispersion or powder form were used to process natural fibres (in this case flax) with PP as matrix in a mat-forming process. Fang et al. [36] applied MAPE in solid form before thermo-mechanical refining of hemp fibres. Coupling agent in solid form and hemp fibres were mixed first and then underwent the defibration process. The results may be different if the coupling agent is added after the defibration process, i.e., via the refiner blow-line and in emulsified form.

It was the objective of this study to compare the effectiveness of low-molecular MAPP with a high graft content of $7 \%$ maleic anhydride when applied in solid (granule) and emulsified forms. The MAPP emulsion was applied using an industrially feasible method, i.e., by using the refiner blow-line. This way, wood fibres can be treated with MAPP and dried afterwards in a continuous process. In addition, the effect of the defibration temperature $\left(150{ }^{\circ} \mathrm{C}\right.$ versus $\left.180{ }^{\circ} \mathrm{C}\right)$ on the composite properties should be evaluated. Formulations based on TMP made from Scots pine (Pinus sylvestris L.) and Robinia (Robinia pseudoacacia L.) wood were prepared. Scots pine is widely cultivated and available in Europe. Robinia is only regionally important in Germany, but worldwide it is the third most often cultivated hardwood species following eucalypt and poplar species [37]. It confers high resistance against wood decay fungi and good strength properties to WPC [38]. Mechanical and physical properties of the WPC made with treated fibres were determined and the fibre surfaces analysed using Fourier-Transform-Infrared (FTIR) spectroscopy and X-ray photoelectron spectroscopy (XPS). Microscopical investigations with original 
and extracted composites were performed to evaluate the distribution of the TMP in the polymer matrix and fibre degradation during processing.

\section{Materials and Methods}

\subsection{Materials}

Isotactic polypropylene (PP) fibres with a length of $6 \mathrm{~mm}$, a melt flow index (MFI) of $13 \mathrm{~g} / 10 \mathrm{~min}$ and a melting point of $165^{\circ} \mathrm{C}$ were used as polymer matrix (Belgian Fibers, Mouscron, Belgium). The density of the PP fibres was $0.91 \mathrm{~g} / \mathrm{cm}^{3}$.

A low-molecular weight, maleic anhydride-modified PP in granular form (MAPP; Licocene ${ }^{\circledR}$ PP MA 7452, Clariant GmbH, Gersthofen, Germany) with a graft (maleic anhydride) content of $7 \%$ was used as coupling agent. Acid number and softening point were approx. $41 \mathrm{mg} \mathrm{KOH} / \mathrm{g}$ and ca. $161{ }^{\circ} \mathrm{C}$, respectively. An emulsion (Permanol 3RC09) based on the same MAPP as above (PP MA 7452) was specially prepared for this project at BYK-Cera B.V. (previously Dick Peters B.V.), Denekamp, the Netherlands. Solids content was $35.5 \%$ and consisted of $27 \%$ MAPP, including $7 \%$ maleic anhydride, and $8.5 \%$ of nonionic emulsifier; $\mathrm{pH}$ was 7.3. An ester wax-based lubricant (Licolub ${ }^{\circledR} \mathrm{H} 12$, Clariant $\mathrm{GmbH}$, Gersthofen) was used to improve extrudability.

Commercially available softwood flour (Lignocel BK 40/90, particle size 300-500 $\mu \mathrm{m}$, J. Rettenmaier \& Söhne GmbH + Co. KG, Rosenberg, Germany) was used as reference wood substrate. This softwood flour is produced in a mechanical process without the influence of high temperature as during the thermomechanical pulping process.

Refiner wood fibres (thermomechanical pulp, TMP) were produced using a laboratoryscale 12 inch $(30.5 \mathrm{~cm}$ ) double disc refiner (Andritz, Graz, Austria) with a refiner gap width of $0.5 \mathrm{~mm}$. Scots pine (Pinus sylvestris L.) and Robinia (black locust; Robinia pseudoacacia L.) wood chips were steamed for $5 \mathrm{~min}$ at $150{ }^{\circ} \mathrm{C}$ and 5 bar pressure, or at $180{ }^{\circ} \mathrm{C}$ and 8 bar pressure. Fibres were discharged through the blow-line either with or without $3 \%$ MAPP emulsion application and dried in a tube drier. The solids content of the emulsion was taken into account for the calculation of emulsion application and formulation weight percentages. The wood moisture content of the fibres after drying was approximately $10 \%(\mathrm{wt})$.

\subsection{Compounding and Extrusion of Wood-Plastic Composites}

WPC formulations are listed in Table 1. The weight percentage of TMP or wood flour in the formulations was kept constant at 70\%. A thermokinetic mixer (type TSHK 100, Papenmeier/Lödige, Paderborn) was used for the preparation of compounds. TMP and wood flour were processed in the thermokinetic mixer without prior drying. A plough-blade mixer (type FM 130 DS, Lödige, Paderborn) was used for cooling and further granulation of the compounds. The moisture content of the compounds after granulation was approx. $1 \%$ (wt.). Compounds were extruded into three-box profiles $(70 \mathrm{~mm} \times 17 \mathrm{~mm}$, wall thickness $4 \mathrm{~mm}$; flat surfaces) on a $54 \mathrm{~mm}$, conical, counter-rotating twin-screw extruder (Battenfeld miniBEX 2-54C). A crammer feeder (type KSW, Kreyenborg GmbH, Münster, Germany) was used to feed the compounds into the extruder. Extrusion temperatures were between $160^{\circ} \mathrm{C}$ and $190^{\circ} \mathrm{C}$.

Table 1. Wood-plastic composites (WPC) formulations. Percentages represent weight-percent.

\begin{tabular}{|c|c|c|c|c|c|}
\hline $\begin{array}{l}\text { TMP Fibres } \\
\text { (Defibration } \\
\text { Temperature) }\end{array}$ & Wood Flour & Polypropylene & $\begin{array}{l}\text { MAPP as } \\
\text { Emulsion }\end{array}$ & $\begin{array}{l}\text { MAPP as } \\
\text { Granules }\end{array}$ & Lubricant \\
\hline $70\left(180^{\circ} \mathrm{C}\right)$ & 0 & 26 & 3 & 0 & 1 \\
\hline $70\left(180^{\circ} \mathrm{C}\right)$ & 0 & 26 & 0 & 3 & 1 \\
\hline $70\left(150^{\circ} \mathrm{C}\right)$ & 0 & 26 & 0 & 3 & 1 \\
\hline $70\left(180^{\circ} \mathrm{C}\right)$ & 0 & 29 & 0 & 0 & 1 \\
\hline $70\left(150^{\circ} \mathrm{C}\right)$ & 0 & 29 & 0 & 0 & 1 \\
\hline 0 & 70 & 26 & 0 & 3 & 1 \\
\hline 0 & 70 & 29 & 0 & 0 & 1 \\
\hline
\end{tabular}




\subsection{Determination of Mechanical and Physical Properties of the Composites}

Following extrusion, specimens for mechanical and physical property testing were machined by conventional techniques. The largest sample dimension was coincident with the extrusion direction. After cutting, specimens were conditioned to constant weight (less than $1 \%$ change during $24 \mathrm{~h}$ ) at $20{ }^{\circ} \mathrm{C}$ and $65 \%$ relative humidity and weighed to the nearest $0.001 \mathrm{~g}$. The flexural strength and modulus of elasticity (MOE) of ten specimens per formulation ( $500 \mathrm{~mm}$ profile length; $340 \mathrm{~mm}$ support span) were determined according to modified DIN EN 310 using a three-point bending test on a universal testing machine (Zwick 1474); test speed was $2 \mathrm{~mm}$ per min. The tensile strength and MOE of ten specimens per formulation were determined on dumb-bell shaped specimens (type 1B) according to DIN EN ISO 527-1 and -2 on a universal testing machine (Zwick 1474); test speed was $2 \mathrm{~mm}$ per min. Charpy impact bending strength of ten specimens per formulation was determined on a pendulum-type test machine (Zwick, type 5102) equipped with a 1 Joule-pendulum according to DIN EN ISO 179-1/1fU for unnotched specimens (type 1) in flat-wise impact direction; specimen size was $80 \mathrm{~mm} \times 10 \mathrm{~mm} \times 4 \mathrm{~mm}$. Support span was $62 \mathrm{~mm}$.

Water absorption and dimensional changes of ten specimens per formulation were determined with a five-hour boiling test according to EN 15534-1 (2018), which is used for production control in industrial WPC extrusion. The thickness and width of the test specimens were the actual dimensions of the profile, whereas the length of the test specimens (parallel to the direction of extrusion) was $100 \mathrm{~mm}$. Specimens were weighed, measured, added to boiling water for five hours and then immediately immersed in cold water. Within two hours after cold water immersion, samples were retrieved, blotted dry with paper towels, weighed and measured again. Water uptake and volume change were determined in percent of the original values.

\subsection{Fourier-Transform Infrared Spectroscopy (ATR-FTIR)}

Samples of TMP treated with emulsified MAPP and untreated fibres were pelletized using a small vacuum press to produce cylindric samples with $10 \mathrm{~mm}$ diameter and 1 $\mathrm{mm}$ to $2 \mathrm{~mm}$ thickness. Emulsified MAPP was freeze-dried prior to analysis. FourierTransform Infrared (ATR-FTIR)-spectra were recorded using an Impact 410 device from Sensir Technologies. The used diamond has a refractive index of 2.4. A spectral range from $550 \mathrm{~cm}^{-1}$ to $4000 \mathrm{~cm}^{-1}$ was measured and the measured reflection was plotted against the wave number. To determine if emulsified MAPP was chemically bound to the fibres, Soxhlet extraction of the fibres using xylene as solvent was performed following an approach similar to Carlborn and Matuana [39]. After extraction, fibres were ovendried and pressed to cylindric samples. ATR-FTIR was then performed using the extracts and residues.

\subsection{X-ray Photoelectron Spectroscopy (XPS)}

The XPS measurements were performed on the pelletized fibres using a PHI 5500 Multitechnique system from Perkin-Elmer, equipped with a $\mathrm{MgK} \alpha \mathrm{X}$-ray source $(1253.6 \mathrm{eV})$ without monochromator. During the measurement, the vacuum was smaller than $8 \times 10^{-9}$ mbar. The collection angle was $45^{\circ}$ and the $X$ ray spot size was $1.1 \mathrm{~mm}$ in diameter. The peak deconvolution and curve fitting was performed with the MultiPak Software V5.0A from Physical Electronics. The spectrum was shifted with reference to the C1s signal at $285.0 \mathrm{eV}$.

\subsection{Soxhlet Extraction and Microscopy}

TMP and wood flour were extracted from the PP matrix using Soxhlet extraction. Small amounts (approximately $3 \mathrm{~g}$ ) of the extruded, ground and dried composite material were used for extraction with xylene as the solvent, as described above. It was determined that the extraction process itself did not influence wood fibre or particle geometry. TMP and wood flour before and after processing were evaluated using a light microscope (Zeiss Axioplan). Small pieces were taken from the extruded profiles and cross and length sections 
cut and polished. Images were taken with a digital camera (ProgRes C14, Jenoptik) and evaluated using the AnalySis program (Olympus). Microscopy was partially performed using fluorescence excitation and suitable filter devices. Images were modified using specific colour settings to achieve optimum contrast.

\section{Results and Discussion}

\subsection{Mechanical Properties of WPC Made with TMP Fibres and Coupling Agent}

The use of MAPP in the formulations had a pronounced effect on the strength properties of the extruded composites, irrespective of the wood species (Scots pine versus Robinia) and the form of MAPP (emulsified versus solid). The strength improvement of WPC due to the use of MAPP is well known $[40,41]$. The maleic anhydride moieties of the MAPP may interact chemically with the hydroxyl groups of wood polymers via hydrogen-bonding or esterification [28]. It has also been proposed that the application of MAPP to wood improves interfacial adhesion by modifying the fibre surface energy and improving the fibre dispersion in the plastic matrix [28,42]. The reaction between the plastic matrix (PP) and MAPP is achieved by physical entanglement. In addition, the PP chain segments of the MAPP can co-crystallize with the thermoplastic matrix.

The results for mechanical properties are shown in Figures 1-5. In each figure, the effects of the refining temperatures and wood species can be compared, as well as the presence (with or without MAPP) and form (emulsified versus solid MAPP) of the coupling agent. The comparison of MAPP in emulsified and solid form was performed at the refiner temperature of $180^{\circ} \mathrm{C}$ only because in high-temperature TMP, fibres are typically coated with lignin as a result of the refining process [43]. It was originally hypothesized that the presence of lignin and/or extractives on the fibre surfaces produced by hightemperature refining increases the hydrophobicity of the surfaces and would improve the compatibility with the hydrophobic polypropylene. In addition, the high yield from high-temperature TMP refining provides a cheaper fibre than other wood fibres such as Kraft pulp.

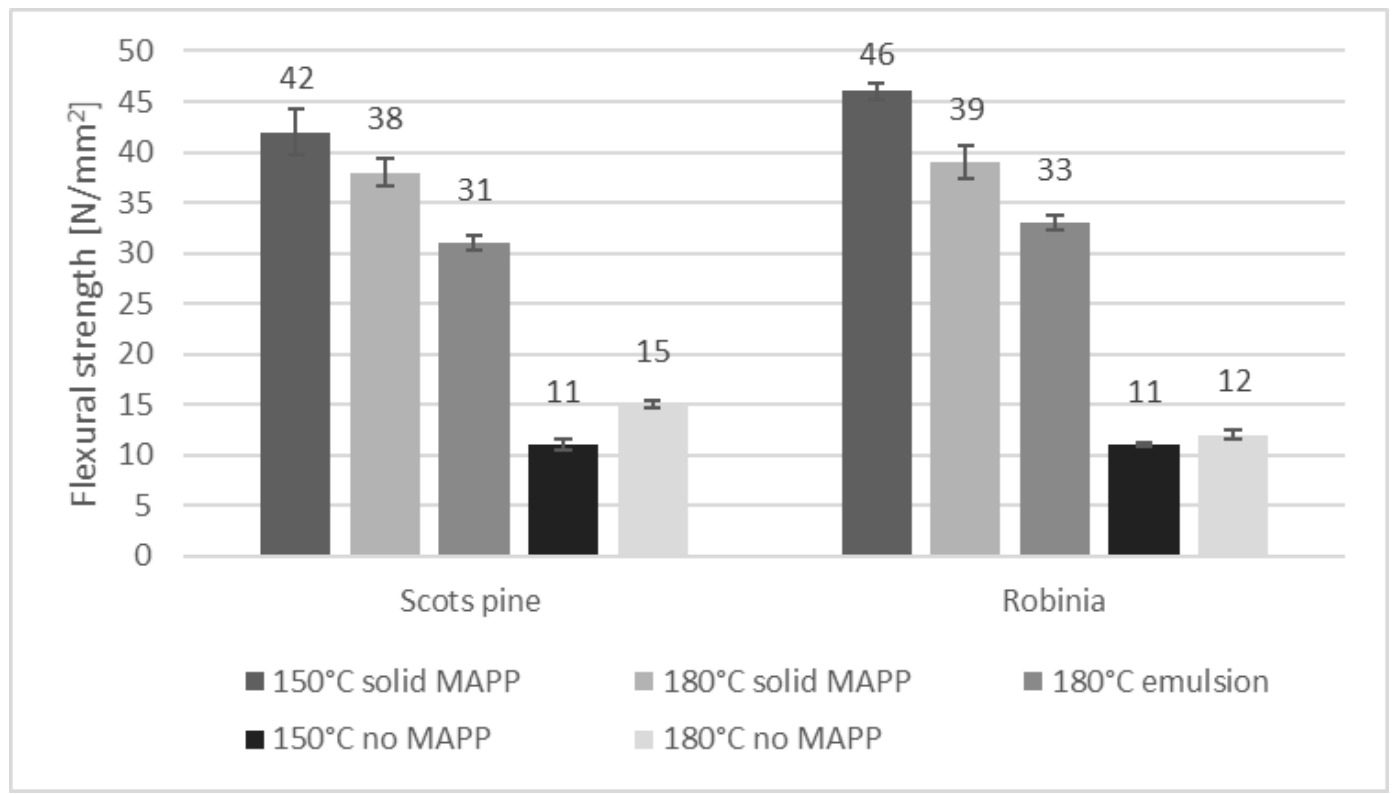

Figure 1. Flexural strength of composites with TMP based on Scots pine or Robinia. For comparison, flexural strength of composites with wood flour (softwood) was $50 \mathrm{~N} / \mathrm{mm}^{2}$ including MAPP (solid) and $16 \mathrm{~N} / \mathrm{mm}^{2}$ excluding MAPP. 


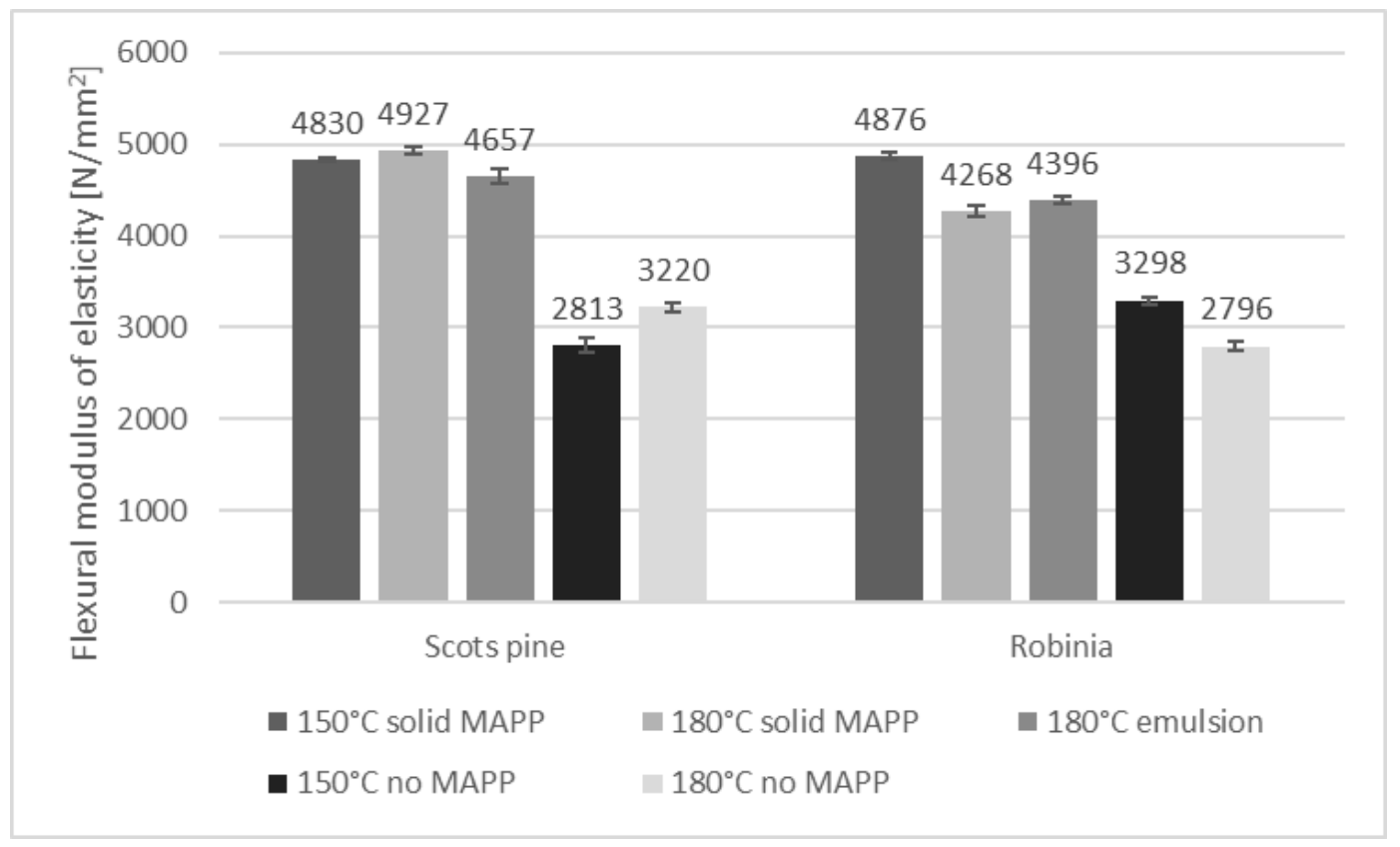

Figure 2. Flexural modulus of elasticity (MOE) of composites with TMP based on Scots pine or Robinia. For comparison, flexural MOE of composites with wood flour (softwood) was $6202 \mathrm{~N} / \mathrm{mm}^{2}$ including MAPP (solid) and $4047 \mathrm{~N} / \mathrm{mm}^{2}$ excluding MAPP.

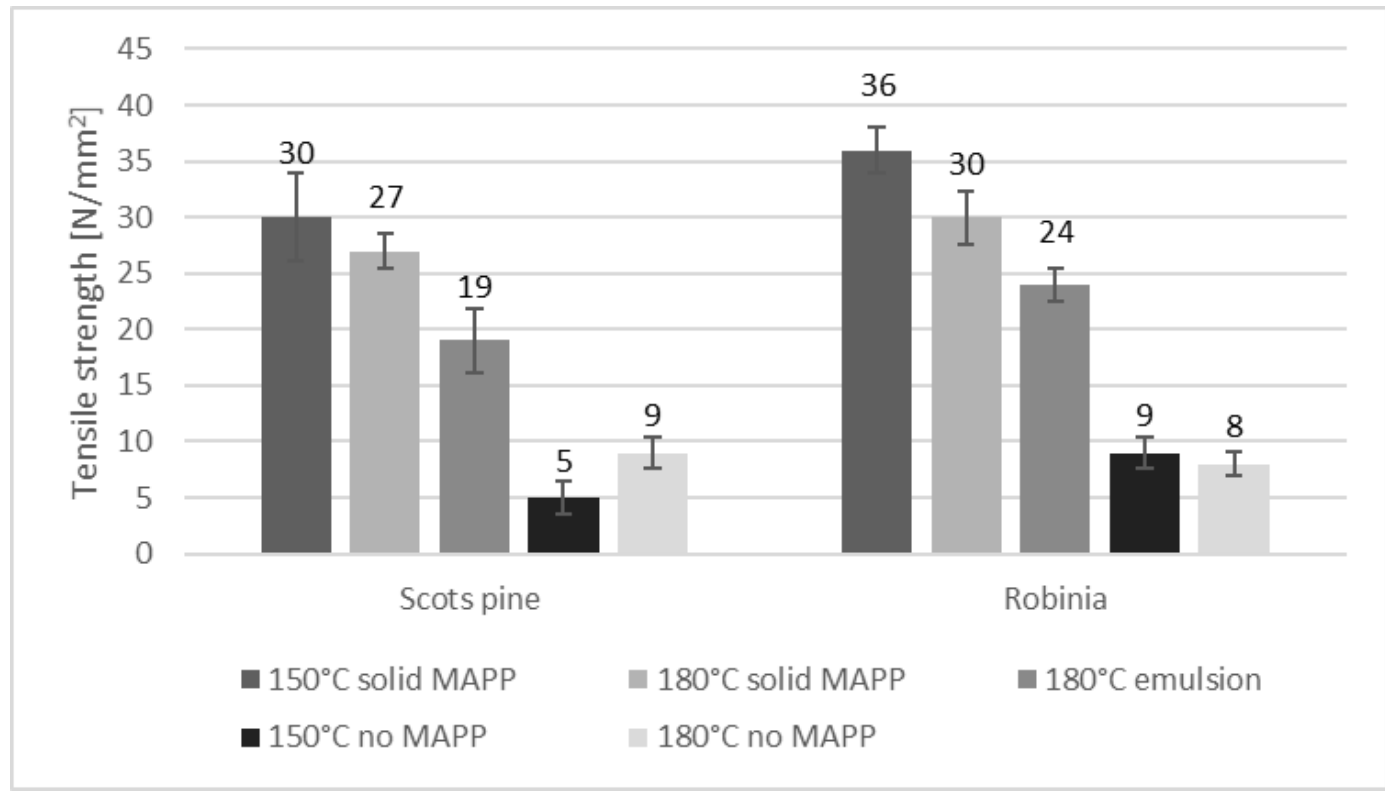

Figure 3. Tensile strength of composites with TMP based on Scots pine or Robinia. For comparison, tensile strength of composites with wood flour (softwood) was $41 \mathrm{~N} / \mathrm{mm}^{2}$ including MAPP (solid) and $11 \mathrm{~N} / \mathrm{mm}^{2}$ excluding MAPP. 


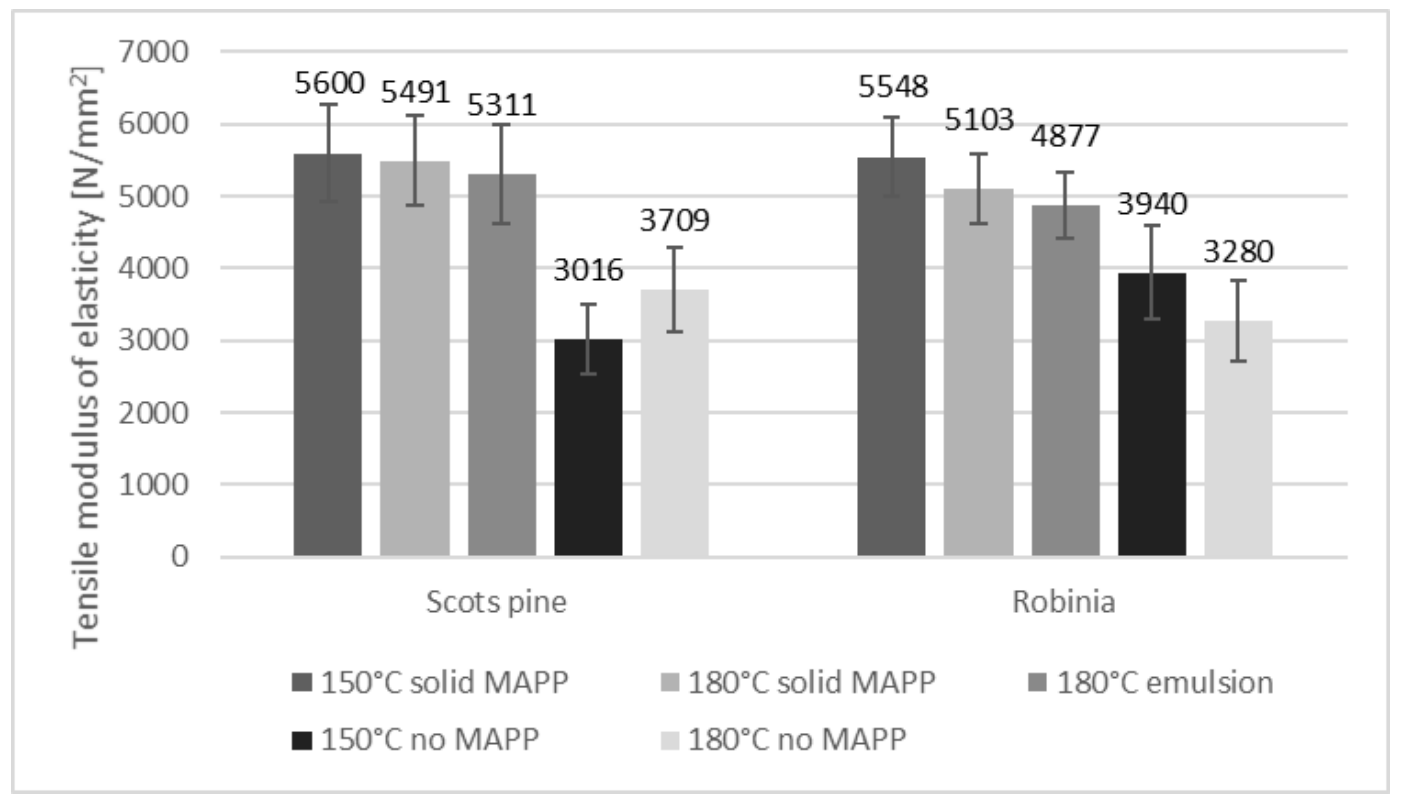

Figure 4. Tensile modulus of elasticity of composites with TMP based on Scots pine or Robinia. For comparison, tensile MOE of composites with wood flour (softwood) was $7169 \mathrm{~N} / \mathrm{mm}^{2}$ including MAPP (solid) and $5826 \mathrm{~N} / \mathrm{mm}^{2}$ excluding MAPP.

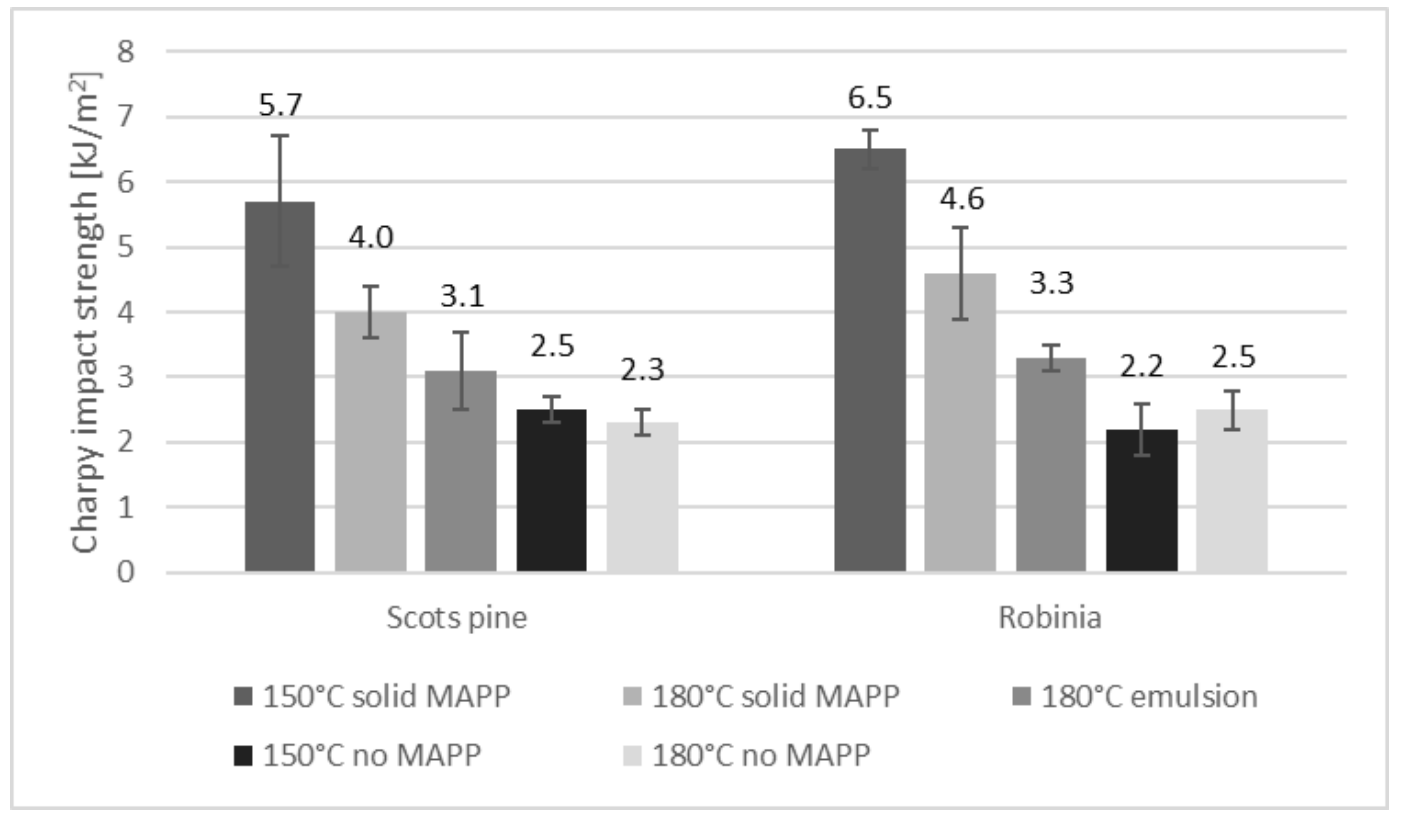

Figure 5. Charpy impact strength of composites with TMP based on Scots pine or Robinia. For comparison, values for composites with wood flour (softwood) were $6.9 \mathrm{~N} / \mathrm{mm}^{2}$ including MAPP (solid) and $2.8 \mathrm{~N} / \mathrm{mm}^{2}$ excluding MAPP.

Figure 1 shows that the highest flexural strength was achieved with solid MAPP at a defibration temperature of $150{ }^{\circ} \mathrm{C}\left(42 \mathrm{~N} / \mathrm{mm}^{2}\right.$ for Scots pine and $46 \mathrm{~N} / \mathrm{mm}^{2}$ for Robinia). An increase in the defibration temperature to $180{ }^{\circ} \mathrm{C}$ reduced flexural strength moderately to $38 \mathrm{~N} / \mathrm{mm}^{2}$ (Scots pine) and $39 \mathrm{~N} / \mathrm{mm}^{2}$ (Robinia). This result contradicted our initial hypothesis as outlined above. It appears that a higher amount of lignin on the fibres has a negative effect on flexural strength if MAPP is used as coupling agent. Assuming that lignin is present on the fibres, the key question is if the lignin is more or less reactive to maleic anhydride than cellulose and hemicelluloses. In a study by Rude and Laborie [44], the chemical interaction between maleic anhydride grafted PP and wood was 
investigated using solid-state carbon-13 cross-polarization magic-angle-spinning nuclear magnetic resonance (13C CP-MAS NMR) spectroscopy. It was concluded that esterification occurs preferentially with lignin. This result is in line with wood modification studies which have shown that lignin is more reactive to anhydrides than cellulose. In addition, it is known that lignin is amorphous and therefore more accessible than cellulose, which is semi-crystalline. It is possible that the accessibility of the MAPP is also controlled by steric hindrance due to the long PP chains on the MAPP backbone.

Because in our investigations the reduction in strength with higher refining temperature was observed for all strength properties (flexural, tensile and impact), it appears that under the conditions in this study, the bonding of the maleic anhydride with the fibre surfaces was hindered when thermomechanical pulping was performed at high temperatures. It is likely that a defibration temperature of $180^{\circ} \mathrm{C}$ causes some thermal degradation of the fibres, which leads to brittleness and strength losses in the composites. If fibres were produced using a mechanical refining process with minimum thermal influence and then used in compounding and extrusion, this may provide a helpful insight. Mechanically ground wood pulp (GWP) is a type of fibre which is processed without thermal treatment. In a study by Méndez et al. [3], GWP was used to produce WPC. PP-based composites reinforced with GWP were made using an internal mixer followed by injection-moulding. When MAPP was used as a coupling agent, the mechanical properties were improved compared to an uncoupled formulation, as could be expected. However, because TMP was not included in the study by Méndez et al. [3] as a reference, it is not possible to conclude if GWP provides superior mechanical performance under the same processing conditions. In another study, the suitability of GWP and three types of TMP for the processing of WPC were compared [4]. The TMP was processed with different temperatures, boiling times and duration, and it was also based on Scots pine wood as in the present study. The authors determined that WPC made with TMP which was processed at the lowest defibration temperature and with GWP showed the best mechanical properties. However, the differences in performance obtained with TMP and GWP were rather small. The good performance of the TMP produced under the mildest temperature conditions was attributed to the lower degree of thermal degradation under milder conditions, similar to what has been found for thermally modified timber. In addition, it was assumed that the lower temperature TMP had a higher share of cellulose and hemicelluloses and a lower share of lignin. During defibration at high temperatures, the lignin, which has the largest share in the middle lamella between cells, is softened. Consequently, defibration with relatively little cell damage and low mechanical defibration force occurs. In contrast, during low temperature defibration, less lignin softening occurs, and more cell damages in the form of ruptures beside the middle lamella are observed. This in turn leads to a higher share of cellulose and hemicelluloses and a lower share of lignin on the fibre surfaces. These results confirm investigations by Miller et al. [45], who reported that radiata pine fibres produced with different pulping methods (thermomechanical and Kraft pulping) with low lignin surface gave better results than fibres with high lignin content on the surface.

Nygård et al. [20], in their research on injection-moulded WPC based on wood fibres (CTMP and TMP for insulation), also assumed that fibre surfaces with a low amount of lignin lead to higher strength properties. They claimed that lignin-rich areas have less $\mathrm{OH}$-groups available for interaction with the coupling agents, which will influence the efficiency of the coupling agents. This contradicts the findings by Rude and Laborie [44], who determined that the coupling agent (MAPP) primarily bonds with lignin and not with cellulose, as mentioned above. However, Rude and Laborie did not use wood fibres in their investigations but the isolated wood components cellulose powder, Kraft pine lignin and maple wood flour. The type of MAPP used (molecular weight, degree of grafting) may also have an influence on the results.

When MAPP was used in granular form and added during the compounding step (Figure 1), flexural strength was 18\% higher (Scots pine) or 15\% higher (Robinia) compared to when MAPP was used as an emulsion and applied to the fibres before compounding 
$\left(38 \mathrm{~N} / \mathrm{mm}^{2}\right.$ versus $31 \mathrm{~N} / \mathrm{mm}^{2}$ for Scots pine fibres and $39 \mathrm{~N} / \mathrm{mm}^{2}$ versus $33 \mathrm{~N} / \mathrm{mm}^{2}$ for Robinia fibres). It can be concluded that under the conditions of this study, the use of emulsified MAPP did not lead to an improvement in the flexural strength of extruded WPC. It is possible that the amount of liquid MAPP (3 wt.\%) applied to the TMP was too low to achieve higher flexural strength values. Compared to cubically shaped wood particles of the same volume, TMP has a larger surface area, which may require a larger amount of MAPP to be effective in achieving good bonding between the fibres and matrix. It is also possible that the type and amount of emulsifier used in the preparation of the liquid MAPP had a negative effect on the mechanical performance of the composite. To determine if the MAPP emulsion was in fact present on the fibres, ATR-FTIR measurements were performed (see next section). To evaluate if the type of emulsifier (non-ionic) used was not suitable, additional experiments were performed using anionic and cationic emulsifiers (results not shown). However, both alternative emulsifiers were less effective. Emulsifiers (surfactants) are classified according to their polar head group. A non-ionic emulsifier has no charged groups in its head group, whereas the head of an anionic surfactant carries a negative charge and that of a cationic surfactant carries a positive charge. Anionic emulsifiers require a cation as counterion which is commonly alkaline, such as sodium or potassium. This alkaline cation interferes with the MAPP by building carboxylates. This means MAPP is blocked and cannot react with the hydroxyl groups in the wood fibres. Cationic emulsifiers carry a positive charge and may directly interfere with the carboxyl groups of MAPP. This would also interfere with the reaction of the MAPP and wood fibres.

When the coupling agent was omitted, flexural strength was significantly reduced to values between 11 and $15 \mathrm{~N} / \mathrm{mm}^{2}$. Interestingly, without MAPP, the higher defibration temperature $\left(180^{\circ} \mathrm{C}\right)$ resulted in higher strength compared to the lower defibration temperature $\left(150^{\circ} \mathrm{C}\right)$. This is in line with our initial hypothesis that the lignin-rich surfaces of high-temperature TMP would lead to better compatibility with the hydrophobic PP matrix and to composites with higher strength. It was shown by Roffael et al. [46] and Schneider et al. [47] that the higher the temperature during thermomechanical pulping, the lower the wettability and the higher the hydrophobicity of the fibres.

Overall, when TMP was used, Robinia fibres performed slightly better compared to Scots pine fibres, which could be due to the higher aspect ratio of Robinia fibres [48]. Commercial softwood flour was used as filler for WPC to serve as a reference for the composites made with TMP. The flexural strength of WPC with wood flour was $16 \mathrm{~N} / \mathrm{mm}^{2}$ without MAPP and $50 \mathrm{~N} / \mathrm{mm}^{2}$ when MAPP was included. Hence, the flexural strength of the WPC was highest when wood flour was used. However, it has to be considered that the wood species used for the production of the wood flour was different and a direct comparison between WPC made with TMP and wood flour is not possible. Microscopical investigations of extracted fibres were performed to analyse why cubically shaped wood particles performed better than the TMP. In most studies dealing with wood-fibre- (TMP and CTMP) based WPC, a reference formulation including wood flour was not included, which makes it difficult to fully evaluate the results. An exception is the work by Stark and Rowlands [5]. They determined that wood fibre (TMP) resulted in higher strengths at filler levels of $20 \%$ and $40 \%$ compared to wood flour composites. In profile extrusion, normally, a much higher wood content is used. It may be that the lower amount of wood fibres/flour used by Stark and Rowlands [5] led to better dispersion in the PP matrix as compared to our work, and that the orientation of the fibres was achieved during injectionmoulding. This may have resulted in a reinforcement effect of the thermoplastic matrix due to the fibres.

Figure 2 shows the results for the flexural modulus of elasticity of WPC made with TMP fibres or wood flour. As was observed for flexural strength, the MOE was strongly increased by the use of MAPP, albeit to a lesser extent. Flexural MOE was higher at the lower $\left(150{ }^{\circ} \mathrm{C}\right)$ refining temperature for Robinia fibres but approximately at the same level for Scots pine fibres. The MAPP emulsion led to lower flexural MOE compared to solid MAPP for Scots pine fibres but not for Robinia fibres. WPC made with commercial 
wood flour and solid MAPP added during compounding displayed higher MOE values $\left(6202 \mathrm{~N} / \mathrm{mm}^{2}\right)$ than WPC based on TMP fibres (in the best case, $4927 \mathrm{~N} / \mathrm{mm}^{2}$ for Scots pine and $4876 \mathrm{~N} / \mathrm{mm}^{2}$ for Robinia). An explanation may be that smaller particles with a lower aspect ratio such as in wood flour can be dispersed more easily in the PP matrix, resulting in better homogeneity and therefore stiffer composites.

In addition to flexural strength properties, tensile strength and MOE for WPC based on TMP and wood flour as a reference were determined (Figures 3 and 4). In this case, similar results as for flexural properties were obtained for the variables investigated (solid versus liquid MAPP, higher versus lower refining temperature, Scots pine versus Robinia, TMP versus wood flour). The maximum tensile strength for TMP was $36 \mathrm{~N} / \mathrm{mm}^{2}$ (Robinia) and $30 \mathrm{~N} / \mathrm{mm}^{2}$ (Scots pine). Again, the higher temperature during defibration decreased the strength. Under the conditions applied, the use of emulsified MAPP did not provide an advantage compared to solid MAPP. However, in general, the application of MAPP resulted in large increases in tensile strength. This confirms results from Nygård et al. [20] for composites made with wood powder, wallboard fibres and CTMP fibres. On the other hand, Nygård et al. [20] determined a significant improvement in tensile strength as well as elongation at break and impact strength for wood fibre reinforced composites compared to wood powder-filled composites. This could be due to differences in processing since they used injection-moulding. Horbens et al. [7] also used injection-moulding to process WPC based on TMP or wood flour and PP as matrix. They determined improved strength properties with TMP-based composites compared to wood flour at a fibre content of $20 \%$ (wt) and higher. Guo et al. [25] reported different results with injection-moulded specimens. They used TMP fibres from a refining process as reinforcing fillers for WPC; however, the exact refining conditions (temperature, pressure, etc.) are not reported. Processing was performed by melt-compounding in a Brabender mixer followed by injection-moulding. It was found that the fibres from various wood species and agricultural sources did not provide significant additional reinforcement compared to wood flour, which is in line with our results from the present study as well as from a previous study [9]. However, it was shown for injection-moulded WPC based on beech wood TMP that an increase in fibre length resulted in an improvement in flexural strength and modulus of elasticity, as well as a decrease in water absorption [9].

The results for Charpy impact bending strength (unnotched) are shown in Figure 5. Impact strength was at the same level when either wood flour or Robinia fibres $\left(150{ }^{\circ} \mathrm{C}\right.$, solid MAPP) were used (approx. $7 \mathrm{~kJ} / \mathrm{m}^{2}$ ), and slightly lower when Scots pine fibres $\left(150{ }^{\circ} \mathrm{C}\right.$, solid MAPP) were used. Solid MAPP was more effective in improving impact strength than emulsified MAPP. When MAPP was omitted, impact strength values were between 2.2 and $2.5 \mathrm{~kJ} / \mathrm{m}^{2}$ for the fibre-based WPC and $2.8 \mathrm{~kJ} / \mathrm{m}^{2}$ for the wood flourbased WPC. As had been observed for flexural and tensile strength, impact strength was higher at the lower refining temperature $\left(150^{\circ} \mathrm{C}\right)$ when MAPP was used. Without MAPP, the differences regarding refiner temperature were minimal. The results for the Charpy impact bending strength of WPC were higher compared to results previously obtained with TMP [6], which could be due to the different shapes of the profiles. In our previous study, test specimens were cut from a $40 \mathrm{~mm}$ tape profile, whereas in this project, specimens were cut from a three-box-profile. In general, WPC impact strength is relatively low in highly filled formulations because the thermoplastic matrix primarily contributes to impact strength. The addition of a large amount of wood particles or fibres to a thermoplastic matrix reduces impact strength noticeably. Values for maximum impact strength with $\operatorname{TMP}\left(6.5 \mathrm{~kJ} / \mathrm{m}^{2}\right.$ for Robinia) determined in this study are in the same range as reported by Migneault et al. [15] for extruded WPC based on short CTMP fibres.

\subsection{Water Absorption and Swelling of WPC Based on TMP Modified with MAPP}

The use of MAPP strongly reduced the water uptake and swelling of the composites made with either TMP or wood flour (Figures 6-8). Without MAPP, water uptake was up to $29 \%$ for WPC made with Robinia fibres and up to $37 \%$ for composites made with 
Scots pine fibres (both at $150{ }^{\circ} \mathrm{C}$ ). Without MAPP, the higher refiner temperature $\left(180^{\circ} \mathrm{C}\right)$ led to lower water absorption of the WPC. This can be attributed to the hydrophobation effect during high-temperature refining. It has been shown that the higher the temperature during thermomechanical refining, the lower the wettability of the fibres, i.e., the higher the hydrophobicity [46,47]. The more hydrophobic fibres may bond better with polypropylene, which in turn will reduce water uptake of the WPC. This effect could be observed for composites with Robinia as well as with Scots pine TMP. The opposite effect was observed when MAPP was included in the formulations. Here, the higher refining temperature $\left(180^{\circ} \mathrm{C}\right)$ resulted in higher water uptake of WPC, especially when Robinia TMP was used (15-16\% water uptake at refiner temperature of $180{ }^{\circ} \mathrm{C}$ and $8 \%$ water uptake at $150{ }^{\circ} \mathrm{C}$ ). It can be assumed that the higher the refiner temperature, the more hydrophilic components will be extracted from the wood, especially hemicellulose, which is the most hydrophilic wood polymer [49]. When these hydrophilic components are extracted from the wood, less hydroxyl groups are available for bonding with the maleic anhydride of the coupling agent, which may result in higher water uptake of the composite.

Another important factor which influences water absorption and swelling of the composites is related to the glass transition temperature of lignin which occurs at high $\left(180^{\circ} \mathrm{C}\right)$ pulping temperatures. Upon exceeding the glass transition temperature, the fibres are likely to be completely encased in lignin, which will reharden on cooling [50]. The reason for this is that under these processing conditions, the fibres tend to separate within the middle lamella or at the interface with the primary wall, rather than through the narrow, interconnected zones of matrix within the cell wall [50]. Thus, the fibres remain intact and are rather rigid. The presence of lignin on the fibres has a strong effect on water absorption and swelling of the composites, which are processed either with or without the coupling agent.

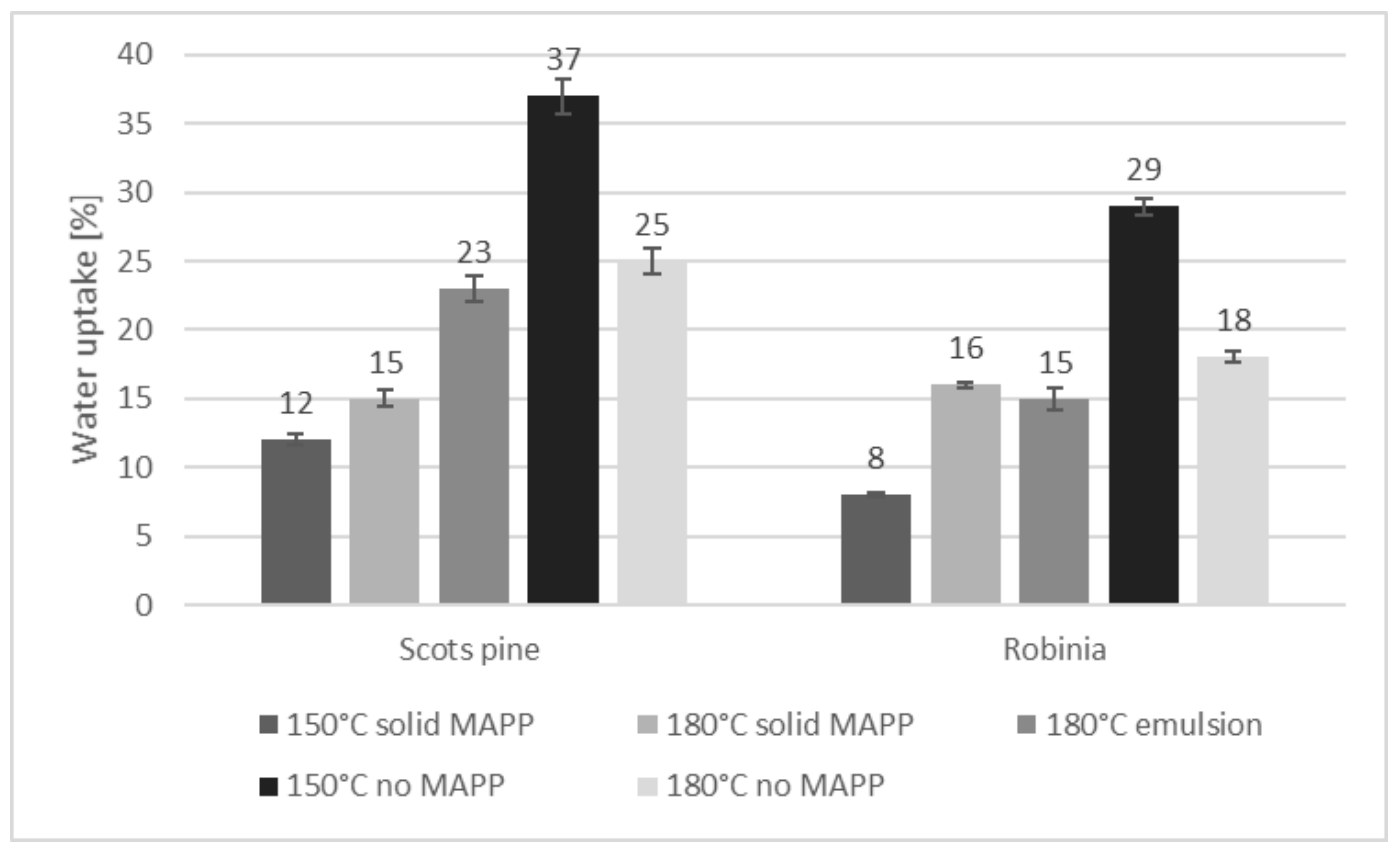

Figure 6. Water uptake of composites with TMP based on Scots pine or Robinia. For comparison, values for composites with wood flour (softwood) were $7 \%$ including MAPP (solid) and 31\% excluding MAPP. 


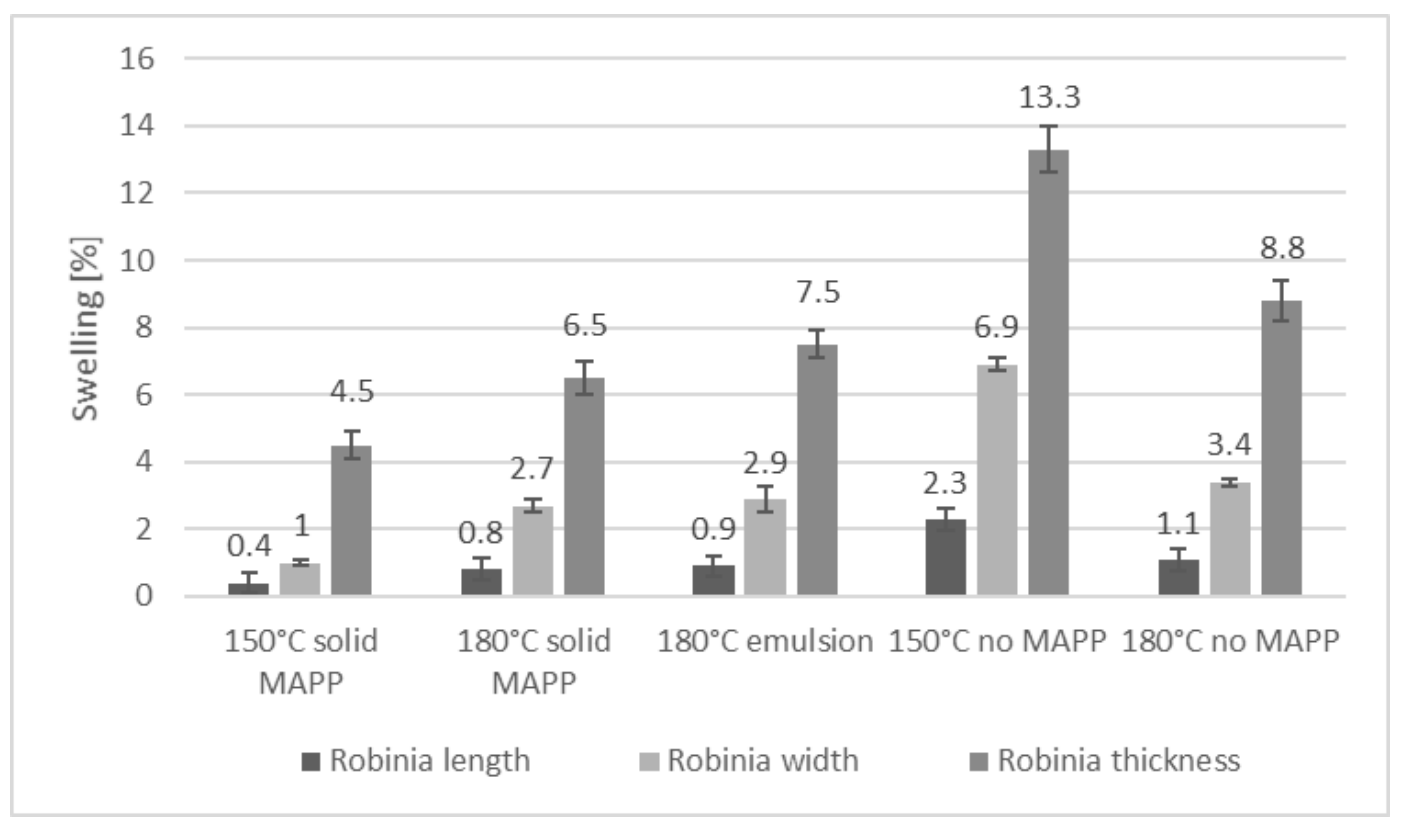

Figure 7. Swelling of composites with TMP based on Robinia after five hours submersion in boiling water. For comparison, values for composites with wood flour (softwood) were $0.3 \%$ (length), $0.7 \%$ (width) and 3.5\% (thickness) including MAPP (solid), and 2.3\% (length), 8.2\% (width) and 16.0\% (thickness) excluding MAPP.

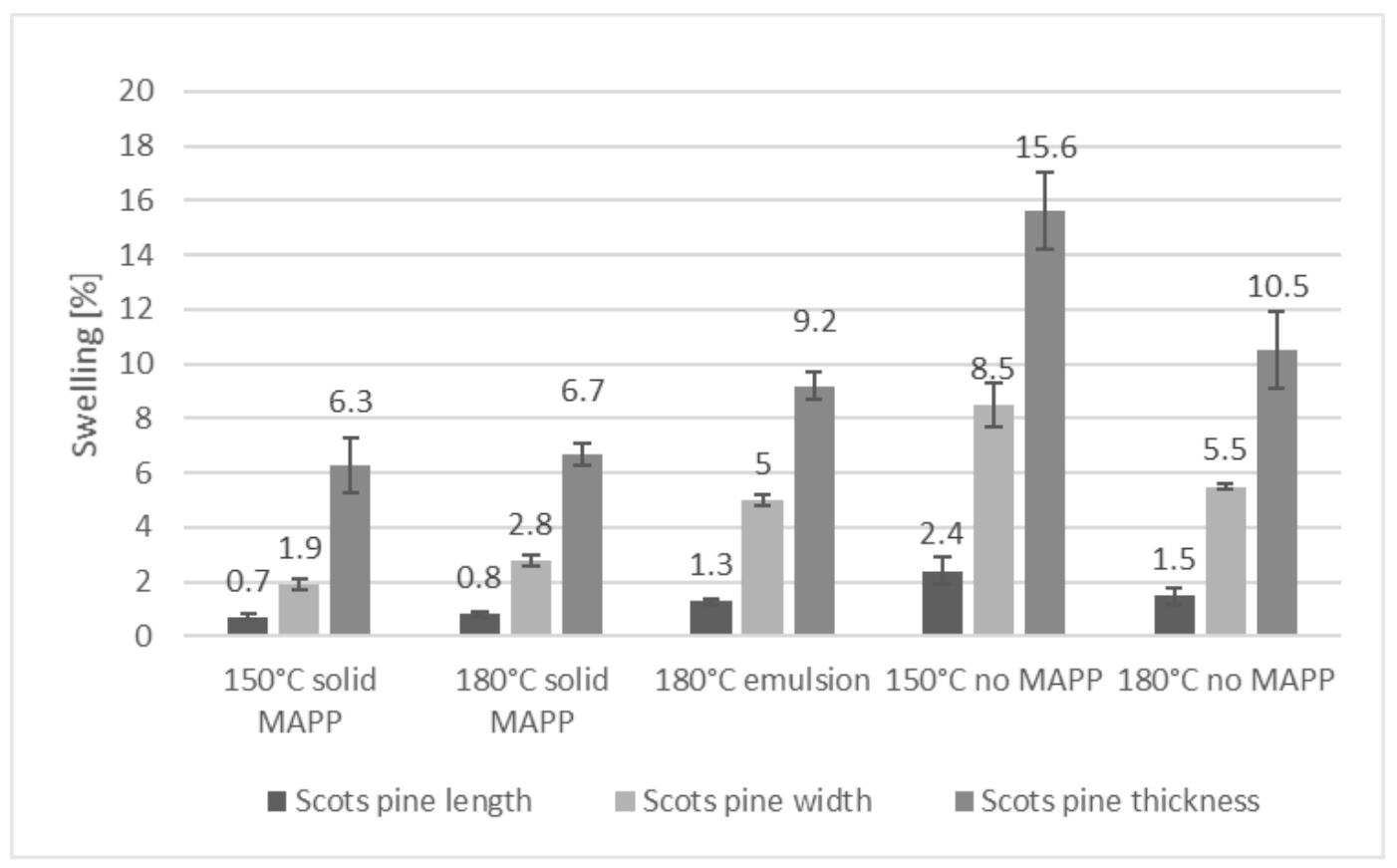

Figure 8. Swelling of composites with TMP based on Scots pine after five hours submersion in boiling water. For comparison, values for composites with wood flour (softwood) were $0.3 \%$ (length), $0.7 \%$ (width) and 3.5\% (thickness) including MAPP (solid), and 2.3\% (length), 8.2\% (width) and 16.0\% (thickness) excluding MAPP.

For WPC with Robinia TMP processed at $180^{\circ} \mathrm{C}$, no difference regarding water uptake during the boiling test was observed whether emulsified or solid MAPP was used (16\% versus 15\% water uptake; Figure 6). However, in the case of Scots pine TMP, MAPP in solid form was more effective in reducing water uptake of WPC than emulsified MAPP (15\% versus 23\% water uptake). Overall, the lowest water uptake of WPC made with TMP was achieved with Robinia $(8 \%)$ which had been processed at $150{ }^{\circ} \mathrm{C}$ and using the 
solid MAPP. This value is in the same range as for WPC with commercial wood flour (7\%). Swelling values after the boiling water test were also similar for WPC with Robinia TMP and wood flour and including MAPP (Figure 7); however, wood flour performed slightly better. For WPC with Robinia TMP, swelling values were $4.5 \%$ in thickness, $1.0 \%$ in width and $0.4 \%$ in length. These values were exceeded when Scots pine TMP was used (Figure 8). For both wood species, the MAPP emulsion led to higher swelling values compared to the solid MAPP. The higher defibration temperature $\left(180^{\circ} \mathrm{C}\right)$ resulted in lower swelling values when no MAPP was used, similar to what could be observed for water uptake.

An interesting result is that when MAPP was omitted, water uptake and swelling of WPC with TMP processed at $180^{\circ} \mathrm{C}$ were lower than for WPC with wood flour. It appears that the thermomechanical treatment caused changes in the hygroscopicity of the fibres. As mentioned above, the glass transition temperature of the lignin which is reached at such high pulping temperatures has a strong influence on the fibre morphology and surface characteristics. Due to the encasing of the fibres with lignin, the fibres are intact and less sensitive to moisture absorption, which leads to swelling.

Values for water absorption and swelling of composites with TMP were higher compared to results shown by Lerche et al. [4], who reported values of 3-4\% for water absorption and $2-3 \%$ for thickness swelling after five hours in boiling water. However, in their work, only $50 \%$ of TMP or GWP were used, compounding was performed using an internal mixer and specimens were injection-moulded. The same processing technique was also used in our previous research and led to similar results in terms of water absorption and swelling for composites made with beech wood TMP [9]. If the wood fibre content is higher than $50 \%$, incomplete encapsulation of the fibres by the polymer matrix can be expected and water uptake and swelling should increase. Lower water absorption for composites processed in an internal (batch) mixer compared to twin-screw extrusion was also reported by Fang et al. [36] for hemp fibre-polyethylene composites. The internal mixing process led to a very homogeneous dispersion of particles or fibres in the polymer matrix.

Ayrilmis et al. [51] subjected Eucalyptus TMP obtained from a commercial MDF plant to a thermal treatment in a laboratory autoclave. The fibres were treated at three different temperatures $\left(120^{\circ} \mathrm{C}, 150^{\circ} \mathrm{C}\right.$ and $\left.180^{\circ} \mathrm{C}\right)$ for 20 or $40 \mathrm{~min}$. Although the treatment was different from a classical thermo-mechanical pulping process and processing was performed using flat-pressing, the results were similar. Thickness swelling and water absorption of the panels significantly decreased with increasing the treatment temperature and time. This was attributed to hydrolysis of the hemicelluloses during thermal treatment, which decreases the hygroscopicity of the lignocellulosic material [52]. Using an anionic MAPP emulsion, Krzysik and Youngquist [34] determined small improvements in water resistance for air-formed wood fibre-PP fibre composites at a high wood fibre level of $85 \%$. The specific air-forming process they used required the use of a coupling agent which can be sprayed on fibres. Hence, they did not include a solid MAPP, and a comparison between emulsified and solid MAPP cannot be made.

\subsection{Comparison of the Mechanical Properties and Water Uptake for Composites with and without MAPP}

In Figure 9, the improvements in strength properties and water uptake due to the use of MAPP are summarized. The addition of MAPP did not affect flexural and tensile modulus as much as flexural and tensile strength, where large increases of up to $500 \%$ were determined. In many formulations, a larger improvement in flexural and tensile strength due to the use of MAPP was found for the TMP-based composites compared to the wood flour-based composites. This confirms results from Stark and Rowlands [5] for injection-moulded composites. However, in their work, strength increases were $86 \%$ at the most, which could be due to lower TMP and wood flour levels in the composites (a maximum of $40 \%$ was used). The reason why larger strength increases due to MAPP were found for TMP-based WPC could be due to the larger surface/volume ratio for TMP compared to wood flour. It appears that more efficient stress transfer from the fibre to the matrix occurred because of the higher aspect ratio of the fibres compared to the wood flour. 


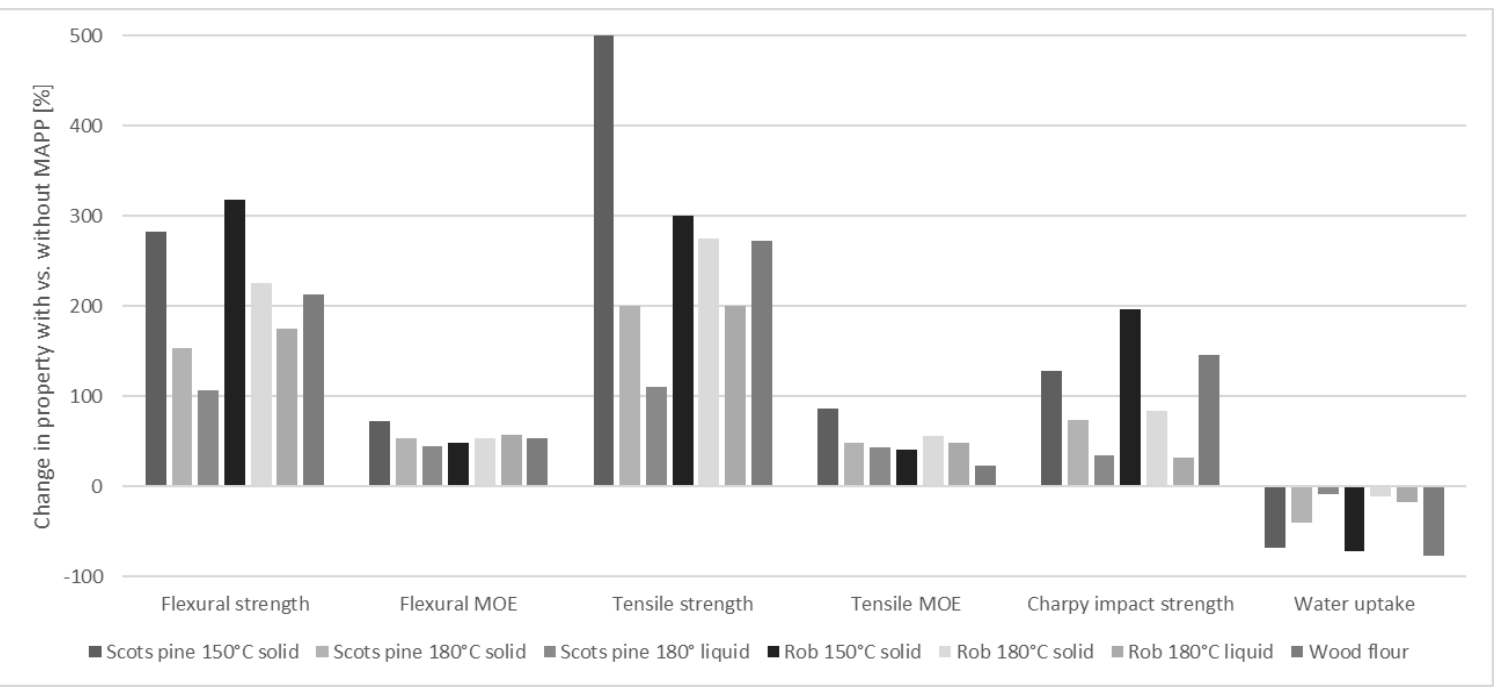

Figure 9. Improvement in mechanical properties and water uptake of WPC due to the use of MAPP (reference: corresponding formulations without MAPP). Solid: MAPP applied as pellets; liquid: MAPP applied as emulsion; rob: Robinia. Temperatures correspond to defibration temperatures during thermomechanical pulping.

The improvement in Charpy unnotched impact energy due to MAPP was mostly higher for the wood flour-based formulation. This result is in contrast to the findings by Stark and Rowlands [5] and was unexpected. If interfacial bonding is good, this should lower the stress concentrations in the composite and increase unnotched impact energy. However, this potential benefit may have been offset in our case by the inhomogeneous distribution of fibres in the matrix.

Water uptake was more decreased when wood flour and MAPP were used (minus $77 \%$ ) compared to when TMP and MAPP were used (minus $72 \%$ at the most). This can be explained with the more homogeneous dispersion of wood flour in the matrix compared to TMP where larger fibres may be overlapping, increasing swelling and causing crack formation.

\subsection{Characterization of TMP Modified with Emulsified MAPP: ATR-FTIR}

The fact that mechanical properties were improved by the application of emulsified MAPP shows that the coupling agent interacted with the TMP. However, emulsified MAPP was not as efficient as solid MAPP. It may be that the emulsifier (surfactant) used in MAPP affected the efficiency of the coupling agent or that a larger amount of MAPP is required when applied as emulsion. Figure 10 shows ATR-FTIR spectra of MAPP in solid and emulsified forms. Two large peaks at 1375 and $1458 \mathrm{~cm}^{-1}$ are visible, which represent the characteristic double peak (deformation vibrations of the $\mathrm{CH}_{3}$-groups) for the polypropylene-backbone [53] of MAPP in both solid and liquid forms. The large peak at approximately $2900 \mathrm{~cm}^{-1}$ represents C-H bonds of the PP-backbone in MAPP (C-H stretching vibrations of $\mathrm{CH}_{3}$ in the PP chain [54]) and of the emulsifier of the liquid MAPP. The emulsified MAPP was oven-dried before the spectra were taken. The emulsifier can be identified by the peak at $1100 \mathrm{~cm}^{-1}$ which is attributed to ether (C-O-C) bonds. In addition, for the emulsified MAPP, a maleic acid peak is visible at $1739 \mathrm{~cm}^{-1}$ [28]. This peak is missing for the solid MAPP. The spectra of the solid MAPP show a characteristic maleic anhydride double peak at $1746 \mathrm{~cm}^{-1}$ [28]. It appears that in the dried emulsion, the nonactivated form of MAPP is present, whereas in the solid MAPP (granules), the activated form is present. The presence of water in the emulsion may lead to an opening of the anhydride ring structure. The MAPP in emulsion form is less reactive due to open ring structure compared to the solid form where the anhydride ring remains reactive. In order to be effective as a coupling agent, MAPP needs to be converted from the maleic acid form into its more reactive anhydride form. According to Felix and Gatenholm [28], the heating 
of MAPP at $180{ }^{\circ} \mathrm{C}$ for five minutes results in anhydride conversion. The activation of emulsified MAPP will neither be achieved during blow-line application nor during fibre drying following blow-line application because temperatures are too low (between $85^{\circ} \mathrm{C}$ and $150{ }^{\circ} \mathrm{C}$ ) and residence time in the dryer is only several seconds; however, activation is assumed to be accomplished during compounding. As strength properties of the composites with emulsified MAPP were improved compared to composites without MAPP, it is evident that activation did occur.

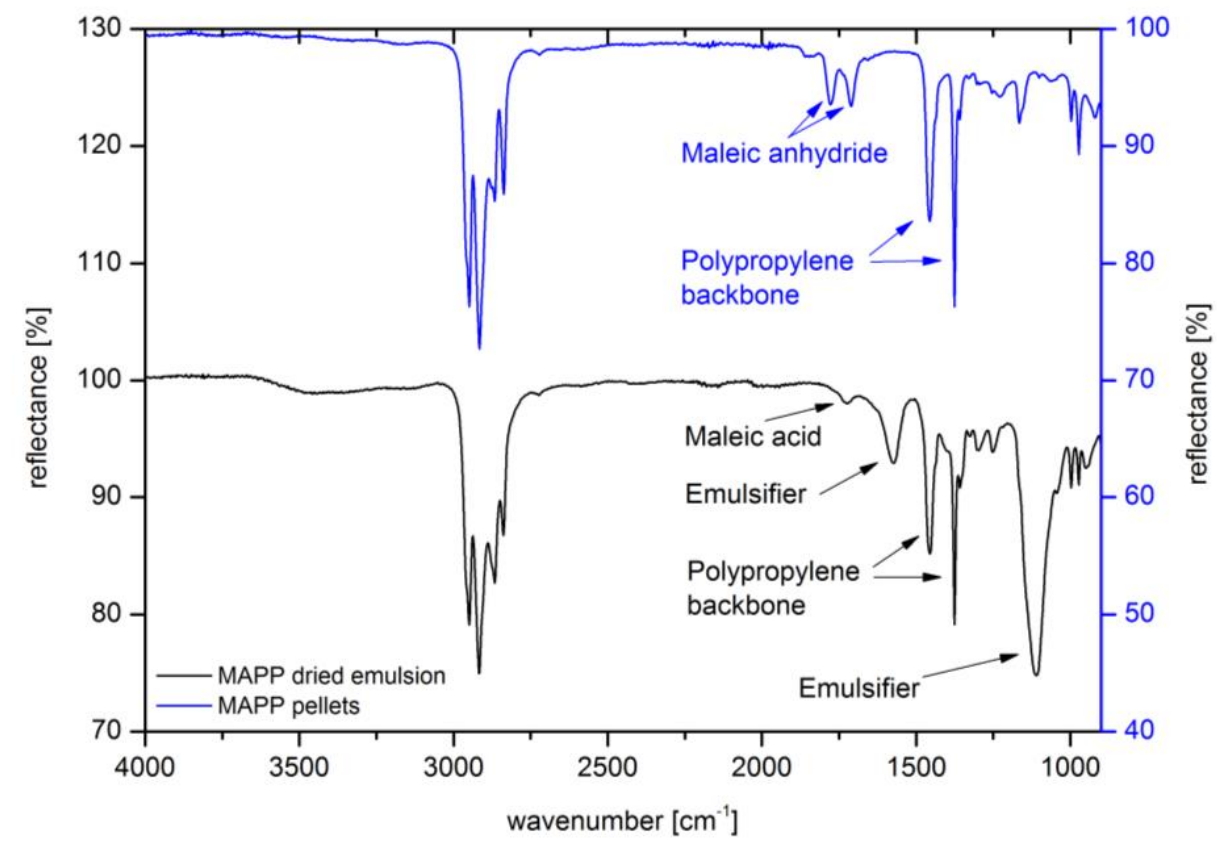

Figure 10. Fourier-Transform Infrared (ATR-FTIR) spectra of MAPP in solid and emulsified forms.

To verify that emulsified MAPP was present on the TMP, ATR-FTIR spectra for the treated and untreated fibres were taken. Untreated fibres display ester groups which absorb near $1730 \mathrm{~cm}^{-1}$, so the confirmation of ester links may be indicated by an increase in the intensity of the absorption bands near $1730 \mathrm{~cm}^{-1}$ [42]. These absorption bands may be associated with carbonyl $(\mathrm{C}=\mathrm{O})$ stretching of acetyl and carboxyl groups in hemicelluloses and lignin, aldehyde in lignin and extractives, and also of esters in lignin and extractives [42]. However, no significant differences were observed near $1730 \mathrm{~cm}^{-1}$ in the spectra of Robinia and Scots pine fibre surfaces with and without liquid MAPP (results not shown). Kazayawoko et al. [42] also found no differences in the FTIR spectra of TMP with and without MAPP. They proposed that the absence of esterification between TMP and MAPP may be due to the presence of lignin on the fibre surface and due to the long polypropylene chains attached to the short anhydride ring (steric hindrance of MAPP).

Although esterification (absorption bands near $1730 \mathrm{~cm}^{-1}$ ) could not be shown using FTIR, we wanted to verify the presence of MAPP on the fibre surfaces. As shown in Figure 10, characteristic peaks of MAPP are visible between 2800 and $3000 \mathrm{~cm}^{-1}$. These bands represent $\mathrm{C}-\mathrm{H}$ bonds of the PP-backbone in MAPP (C-H stretching vibrations of $\mathrm{CH}_{3}$ in the PP chain [54]). Figure 11 shows spectra of treated and untreated fibres as well as of the emulsified, freeze-dried MAPP. It can be seen that the treated fibres display the characteristic peaks of MAPP, whereas these peaks are missing in the spectra of the untreated fibres. This indicates that MAPP is indeed present on the treated fibres. 


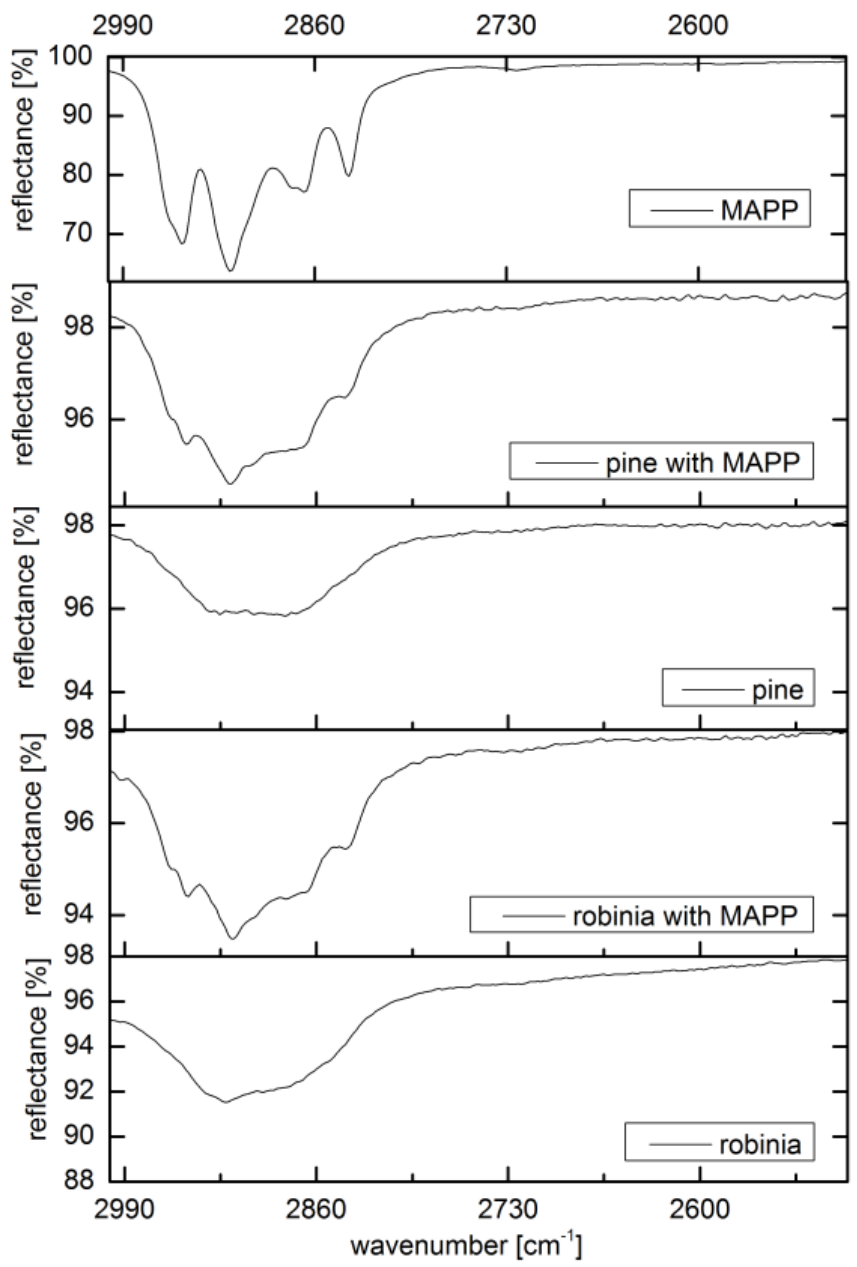

Figure 11. ATR-FTIR spectra of treated and untreated fibres as well as of the emulsified, freezedried MAPP.

To determine if the MAPP had reacted with the fibres (covalent bonding), the treated fibres were extracted using xylene to remove any unbound MAPP, and further FTIR spectra were taken (Figure 12). Figure 12 shows the results for extracts of Robinia fibres between 3000 and $2600 \mathrm{~cm}^{-1}$. It can be seen that the spectra for the liquid MAPP (freezedried) and the extract of the treated fibres are almost identical, in contrast to the spectra of the untreated Robinia extract (bottom of Figure 12). This indicates that under the conditions applied, a least part of the MAPP had not chemically reacted with the fibres. As explained above, this could be due to the presence of the maleic acid form of the coupling agent. Carlborn and Matuana [55] modified wood particles with MAPP through a continuous reactive extrusion process and reported that under the conditions of their study, esterification occurred. Since they did not use a MAPP emulsion but MAPP in solid form, it can be expected that the more reactive anhydride was present. Unreacted maleated polyolefins were removed with a 24-h Soxhlet extraction. Very little difference in the spectra of the modified wood particles after a first and second extraction was found in their study, which provided evidence that the maleated polyolefins were chemically bonded to the wood particles. 


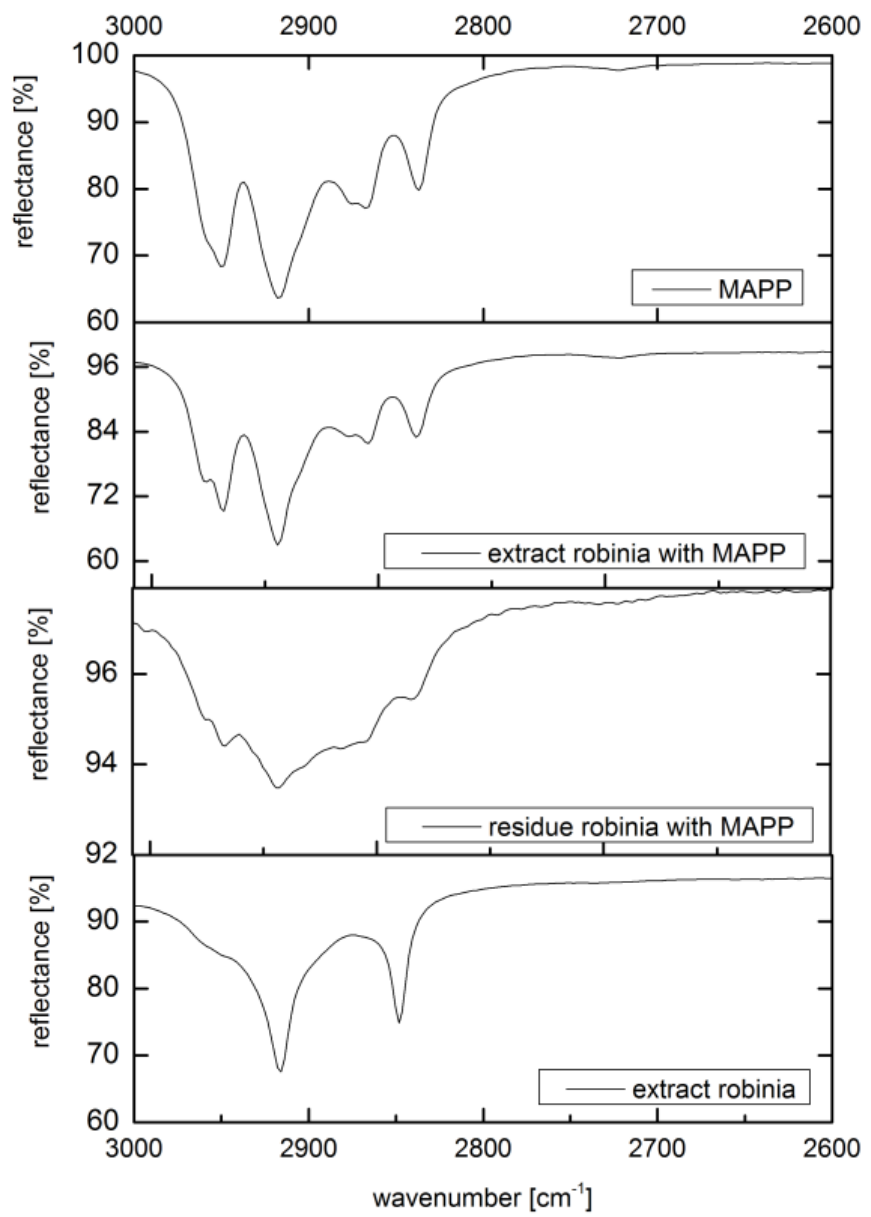

Figure 12. ATR-FTIR spectra of extracts of Robinia TMP with and without emulsified MAPP and of residue.

In addition to the spectra of the extract, the residue was also investigated. In the spectra of the residue, characteristic bands of the MAPP are visible; however, they are very weak. In the spectra of the Robinia wood alone (Figure 11), these are not visible. This in turn shows that a small part of the MAPP was bound to the wood. In summary, some ester links could be detected between TMP and MAPP using ATR-FTIR. Although unbound MAPP was detectable in the extract, it could be shown that some chemical bonding between the coupling agent and TMP occurred. It appears that ester links between wood components and maleic anhydride are not the key determinants for mechanical property improvement in the composites. The effectiveness of MAPP to improve the mechanical properties of WPC was attributed by Kazayawoko et al. [42] to a compatibilization effect, which is accomplished by reducing the total wood fibre surface free energy, improving the polymer matrix impregnation, improving fibre dispersion and orientation and enhancing the interfacial adhesion through mechanical interlocking. Qiu et al. [56] showed that the efficiency of MAPP could be significantly improved when cellulose fibres were pre-treated with 1,6-diisocyanatohexane. Through the reaction of the free superficial hydroxyl groups of cellulose and the NCO group of diisocyanate, the polarity and hydrophilicity of cellulose fibre was reduced, and therefore the compatibility of the cellulose fibres and PP matrix was improved. Due to the imidization reaction of the NCO group and the anhydride group of MAPP, more MAPP chains could be attached to the cellulose fibres due to better accessibility of reactive sites. 


\subsection{Characterization of TMP Modified with Emulsified MAPP: X-ray Photoelectron Spectroscopy (XPS)}

An additional technique, X-ray photoelectron spectroscopy (XPS) or electron spectroscopy for chemical analysis (ESCA), was used to obtain information on the chemical composition of the fibre surfaces. During XPS of solids, the material surface is irradiated by well-defined short-wave electromagnetic radiation. By absorbing the radiation, electrons are emitted from the core layer of atoms in the surface layer which reflect the discrete binding energies of the electrons present in the solid [57]. The XPS technique has been used in various applications to characterize chemical modifications on wood surfaces, for example, surface analysis of different wood species [58], surface characterization of chemically modified pulp and wood [59], evaluation of surface lignin on cellulose fibres [60] and weathering of WPC [61]. Felix and Gatenholm [28] used XPS to study the functioning of maleated PP on cellulose fibres and observed that the treatment made cellulose fibre more hydrophobic, as indicated by the decrease in the oxygen-carbon ratio. Carlborn and Matuana $[39,55]$ employed XPS to verify the esterification reaction between wood particles and maleated polyolefins, which was initiated by a reactive extrusion process.

In lignocellulosic fibres, four distinct peaks can be resolved in XPS spectra, corresponding to the four chemical environments of carbon (Table 3). The $\mathrm{C} 1$ peak is mainly due to $\mathrm{C}-\mathrm{C}$ and $\mathrm{C}-\mathrm{H}$ bonds (lignin and extractives), the $\mathrm{C} 2$ and $\mathrm{C} 3$ peaks are due to $\mathrm{C}-\mathrm{O}, \mathrm{C}=\mathrm{O}$ and $\mathrm{O}-\mathrm{C}-\mathrm{O}$ bonds (lignin, cellulose and hemicelluloses), and the $\mathrm{C} 4$ to $\mathrm{O}-\mathrm{C}=\mathrm{O}$ bonds [56]. Binding energies and chemical shifts for the carbon atoms in organic compounds have been measured and tabulated. In Table 3, binding energies for the $\mathrm{C} 1$ to $\mathrm{C} 4$ carbon types of lignocellulosic materials are shown. Carbon types C2, C3 and C4 display increasing binding energies. Based on XPS scans, the $\mathrm{O} / \mathrm{C}$ ratio and the relative amounts of the different carbons on the surface can be calculated. These amounts are different, for example, in different pulp components where the amount of $\mathrm{C} 1$ carbon decreases in the order extractives $>$ lignin $>$ carbohydrates [57]. Thus, for example, the amounts of lignin and extractives on the surface can be estimated by analysing spectra recorded before and after extraction.

The elemental composition and oxygen-carbon ratio of untreated Robinia TMP produced at either $150{ }^{\circ} \mathrm{C}$ or $180{ }^{\circ} \mathrm{C}$ are shown in Table 2. For comparison, commercial softwood flour was included. The theoretical $\mathrm{O} / \mathrm{C}$ ratio of pure cellulose is 0.83 (five oxygen atoms per six carbon atoms), and it ranges from $0.3-0.4$ for lignin and is about 0.1 for extractives [62]. Accordingly, Migneault et al. [62] reported that lignin-free, cellulose rich cellulose pulp with low extractives content showed the highest $\mathrm{O} / \mathrm{C}$ ratio among the fibres tested (0.71). Bark fibres had the lowest $\mathrm{O} / \mathrm{C}$ ratios at 0.17-0.18.

Table 2. Elemental composition and oxygen-carbon ratio of Robinia TMP and commercial softwood flour as obtained by XPS survey spectra.

\begin{tabular}{cccc}
\hline Wood Substrate & C (\%) & O (\%) & O/C (\%) \\
\hline Wood flour & 77.2 & 22.9 & 29.6 \\
Robinia TMP without MAPP, produced at $150{ }^{\circ} \mathrm{C}$ & 80.9 & 19.1 & 23.6 \\
Robinia TMP without MAPP, produced at $180^{\circ} \mathrm{C}$ & 80.4 & 19.6 & 24.4 \\
Robinia TMP with MAPP, produced at $180^{\circ} \mathrm{C}$ & 80.5 & 19.5 & 24.2 \\
\hline
\end{tabular}

Table 3. Binding energies of different oxidation states of carbon atoms from the X-ray photoelectron spectroscopy (XPS) high-resolution C1s spectra of lignocellulosic materials [63,64].

\begin{tabular}{cccc}
\hline Carbon Atom Class & Chemical Bond(s) & Binding Energy (eV) & Main Wood Component \\
\hline C1 & C-C $/ \mathrm{C}-\mathrm{H}$ & $285.0 \pm 0.4$ & Lignin, extractives \\
C2 & C-O & $286.5 \pm 0.4$ & Carbohydrates \\
C3 & C $=\mathrm{O} / \mathrm{O}-\mathrm{C}=\mathrm{O}$ & $288.0 \pm 0.4$ & Carbohydrates \\
C4 & O-C $=\mathrm{O}$ & $289.5 \pm 0.4$ & Lignin and extractives \\
\hline
\end{tabular}


In our results, it can be seen that softwood flour is more hydrophilic than TMP, indicated by the higher $\mathrm{O} / \mathrm{C}$ ratio of $29.6 \%$ compared to approximately $24 \%$ for the Robinia TMP. This may be attributed to the higher amount of hydroxyl groups present on wood flour compared to the TMP. The TMP surface consists largely of residual lignin (less hydroxyl groups) because at high temperature during the refining process, the zone of failure occurs in the lignin-rich middle lamella. Minor differences regarding defibration temperature $\left(150^{\circ} \mathrm{C}\right.$ versus $\left.180^{\circ} \mathrm{C}\right)$ were observed for $\mathrm{O} / \mathrm{C}$ ratios. In addition, it was found that under the conditions of this study, the treatment of Robinia fibres with MAPP only had a marginal effect on O/C ratio (24.2\% including MAPP versus $24.4 \%$ without MAPP).

The results of the $\mathrm{C} 1 \mathrm{~s}$ high-resolution spectra fitting are shown in Table 4. For comparison, values for cellulose, lignin and extractives (literature data) were included. The C1 carbon type in the lignocellulosic substrates may be attributed to aliphatic and aromatic carbons in lignin and extractives [42]; compare Table 3. The slightly higher $\mathrm{C} 1$ value for Robinia TMP produced at $180{ }^{\circ} \mathrm{C}(69.1 \%)$ compared to the TMP made at $150{ }^{\circ} \mathrm{C}(68.1 \%)$ indicates that a higher amount of lignin is present on the fibres which were defibrated at the higher temperature. This indicates that the $180^{\circ} \mathrm{C}-\mathrm{TMP}$ is more hydrophobic than the $150{ }^{\circ} \mathrm{C}$-TMP as expected. Wood flour shows a lower C1-value $(64.8 \%)$ and is more hydrophilic than the refiner fibres. The C1-value of TMP with MAPP (62.2\%) was lower than C1 of TMP without MAPP $(69.1 \%)$, which was surprising because of the expected contribution of the coupling agent to an increase in $\mathrm{C} 1$ (C-C- and C-H-bonds of the PPbackbone in MAPP). Most of the $\mathrm{C} 1$ carbon can be attributed to aliphatic and aromatic carbons in lignin and extractives, but in the case of MAPP-treated fibres, the coupling agent should also contribute to $\mathrm{C} 1$. A possible explanation could be that the emulsifier and other additives in the liquid MAPP may have hindered the enrichment of PP at the fibre surface. Kazayawoko et al. [42] treated TMP pulp with increasing concentrations of MAPP and found that with increasing concentration of the coupling agent, C1-percentages increased. However, they used a solid type of MAPP and a different processing method.

Table 4. Results of the $\mathrm{C} 1 \mathrm{~s}$ high resolution spectra fitting.

\begin{tabular}{|c|c|c|c|c|}
\hline Wood Substrate & C1 (\%) & $\mathrm{C} 2(\%)$ & C3 (\%) & $\mathrm{C} 4(\%)$ \\
\hline Wood flour & 64.8 & 24.5 & 8.1 & 2.6 \\
\hline $\begin{array}{l}\text { Robinia TMP without MAPP, } \\
\text { produced at } 150{ }^{\circ} \mathrm{C}\end{array}$ & 68.1 & 23.9 & 6.3 & 1.7 \\
\hline $\begin{array}{l}\text { Robinia TMP without MAPP, } \\
\text { produced at } 180^{\circ} \mathrm{C}\end{array}$ & 69.1 & 22.5 & 6.1 & 2.4 \\
\hline $\begin{array}{c}\text { Robinia TMP with MAPP, produced } \\
\text { at } 180^{\circ} \mathrm{C}\end{array}$ & 62.2 & 32.7 & 4.2 & 0.9 \\
\hline Cellulose * & - & 83 & 17 & - \\
\hline Lignin * & 49 & 49 & 2 & - \\
\hline Extractives * & 93 & 5 & - & 2 \\
\hline
\end{tabular}

* Data from Dorris and Gray [63].

C2 carbon may be attributed to primary and secondary alcohols in lignin and extractives [42]. C2 values were slightly higher for wood flour than for the TMP (without MAPP). The emulsifier used with the MAPP contains ether bonds (C-O-C), and therefore, $\mathrm{C} 2$ can be expected to be higher for TMP when MAPP is used. C3 carbon may represent aliphatic and aromatic ethers in lignin and extractives as well as carbonyl groups (in esters, aldehydes, ketones or carboxylics) in lignin and extractives, e.g., fatty acids. C4 carbon may be related to esters and carboxylic acids in lignin and extractives. C3- and C4-percentages decreased when MAPP was applied to the fibres, which is in accordance with the results from Kazawayoko et al. [42]. The reduction in C4 content may indicate that esterification between wood fibres and maleated polypropylene did not occur. On the other hand, esterification may have taken place but the resulting ester links were covered up by the long polypropylene chains so they cannot be easily detected. It can be concluded that chemical bonding 
(esterification) of the maleic anhydride and hydroxyl groups of the wood fibres may have been hindered by the presence of the polypropylene chains of the MAPP. In addition to this steric hindrance, the nature of the wood fibre, the experimental (processing) conditions and the concentration of lignin on the fibre surfaces influence the esterification reaction. Especially lignin may play an important role as it is known to have very few available reactive hydroxyl sites [42]. Pickering et al. [65] used a strong alkali $(\mathrm{NaOH})$ treatment to remove lignin as well as hemicellulose and other alkali soluble compounds from fibre surfaces to increase the number of reactive hydroxyl groups on the fibre surfaces available for chemical bonding. In a following study [66], they determined that fibre pre-treatment with $\mathrm{NaOH}$ reduced strength but improved Young's modulus. In this case, high temperature thermo-mechanically pulped radiata pine wood fibre was used.

Migneault et al. [62] tried to explain the differences in mechanical properties of WPC with surface chemical characteristics. The fibre surfaces of different wood species used for WPC, including bleached cellulose pulp and bark samples, were investigated. They concluded that fibres with carbohydrate rich surfaces led to stronger WPC because the coupling between the matrix (in this case, high-density polyethylene (HDPE)) and fibres using MAPE was achieved with polar sites mostly present on carbohydrates. Conversely, fibre surfaces which are rich in lignin and extractives do not have oxidized functions for the esterification reaction with the coupling agent, which leads to lower mechanical properties. These conclusions agree with our results.

3.6. Microscopical Analysis of TMP and Wood Flour before and after Processing and of Composites Made with MAPP-Treated TMP

Figure 13 shows wood flour, Scots pine TMP and Robinia TMP before compounding and after profile extrusion followed by Soxhlet extraction to investigate the differences in particle and fibre morphology due to processing. Wood flour consists of more or less cubically shaped particles of low length-to-diameter (L/D) ratio. For example, commercial pine wood flour displays a L/D ratio of 3.3 to 4.5 [5]. In contrast, the L/D ratio of TMP may be more than 10:1 and is typically in the order between 20:1 and 70:1 or higher [1] In addition, the bulk density of wood flour is higher than that of TMP. Values for bulk density (ratio of weight of packed material divided by the internal volume of a column) are reported as $0.160 \mathrm{~g} / \mathrm{cm}^{3}$ for TMP and $0.824 \mathrm{~g} / \mathrm{cm}^{3}$ for wood flour [67].

TMP consists of fibres produced from wood chips by a mechanical refining process at high temperature and pressure, whereas wood flour is processed by grinding solid wood using, for example, disc mills or hammer mills. Accordingly, wood flour is usually a mixture of broken fibres and fibre bundles and is rather rough and rigid. In contrast, TMP consists of slender and fluffy fibres with a lignin-rich surface. TMP consists mostly of single, fibrillated fibres, but fibre bundles, particles and flour are also present. The composition of TMP is therefore quite inhomogeneous, and the fibre surface chemistry is different from wood flour. Roffael et al. [68] reported that increasing the temperature during thermomechanical pulping decreases fibre length, cell width and fibre wall thickness. In addition, the amount of fine fibres and the curl factor is increased. These factors were used to explain the decreased flexural strength of MDF panels made with fibres produced at high temperatures [68]. In addition, hornification, which addresses the irreversible structural changes in pulp fibres during drying, may have occurred. When pulp fibres are dried, they lose their conformability and swelling capacity, which can be observed as inferior strength properties and bulkier sheet [69]. The phenomenon leading to the loss of swelling and the changes in the pulp properties during a drying-and-rewetting cycle has been called hornification [70]. It has been suggested that in addition to stiffening and loss of swelling, a change in the surface properties, or surface inactivation of the fibres, may impair the bonding potential of fibres. 


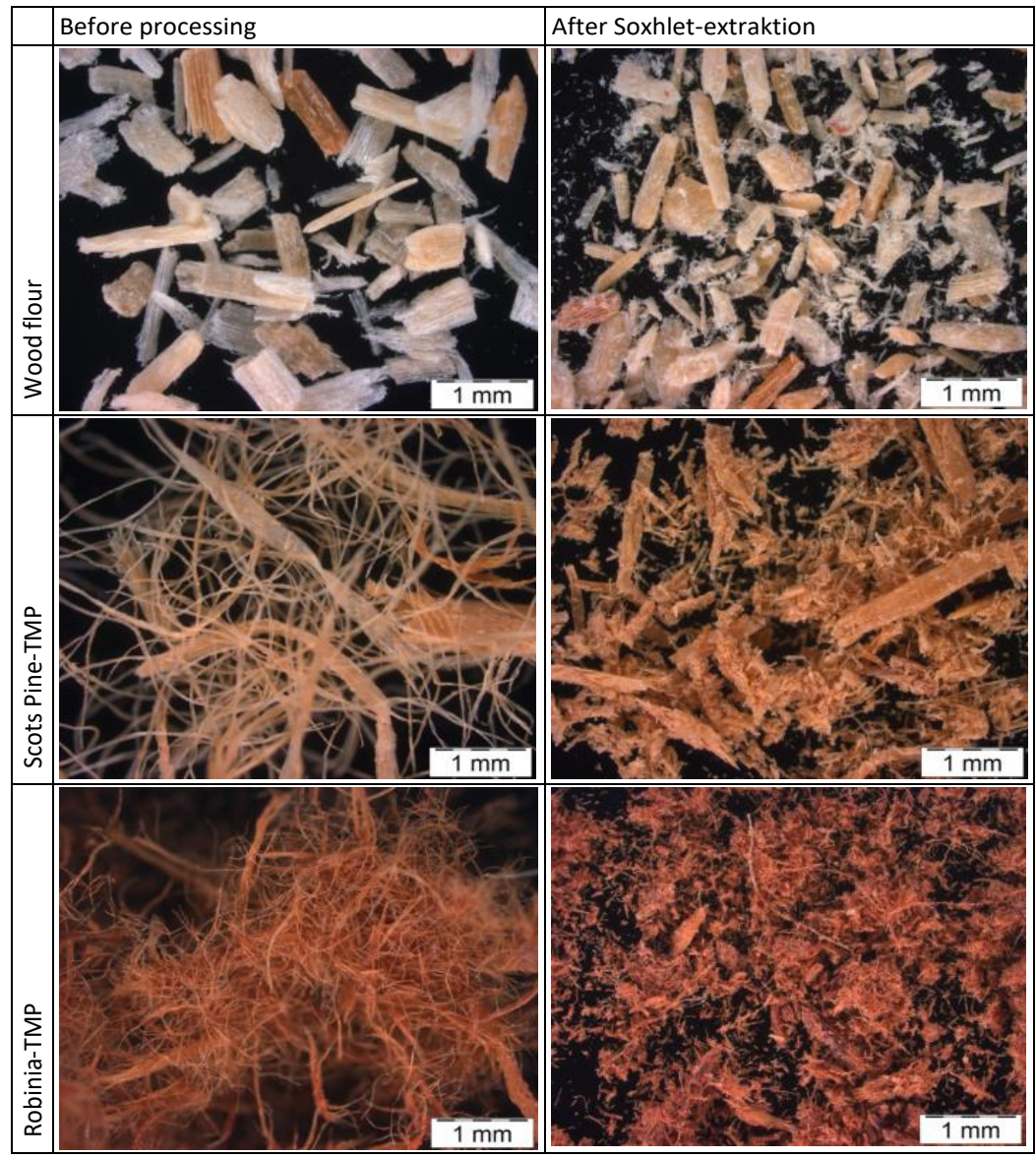

Figure 13. TMP and wood flour observed with reflected light microscope and dark field illumination before compounding (left) and after profile extrusion followed by Soxhlet extraction (right). Magnification 25-fold.

Figure 13 shows the differences in Scots pine and Robinia TMP before processing, which are partially due to their anatomical composition. Scots pine has relatively long fibres (tracheids) of up to $3.1 \mathrm{~mm}$ length and a fibre-length/diameter ratio of 70-103 (calculated based on Wagenführ [48]). Robinia has relatively short fibres (so-called libriform fibres) of up to only $1 \mathrm{~mm}$ length. However, the $\mathrm{L} / \mathrm{D}$ ratio of the Robinia fibres is 112 and therefore higher. It is not the particle length which affects strength properties but rather the lengthto-diameter $(\mathrm{L} / \mathrm{D})$ ratio [5]. This means that the smaller the fibre diameter, the shorter the fibre length may be to accomplish a reinforcement (critical fibre length [8]).

After agglomeration in the heating-cooling mixer and profile extrusion, the TMP was severely degraded and a large part of the material lost its fibrous shape (Figure 13, right). The Robinia TMP before and after processing was of darker colour due to the intensely coloured heartwood. The softwood particles retained their shape during processing more than the fibres did since they are based on ground solid wood and did not experience any defibrillation under thermal exposure, which may increase their resistance against deformation during compounding and extrusion.

Figure 14 shows longitudinal and transversal sections of the composites under UV fluorescence with wood flour (top), Scots pine TMP (centre) and Robinia TMP (bottom). The longitudinal sections show that the particles of the wood flour as well as the TMP fibres are more or less oriented along the extrusion direction. Due to the wide variety in the size of the fibrous material and fine particles present in TMP, the distribution of the TMP components in the polymer matrix is more heterogeneous compared to the wood flour, which consists of similarly shaped particles. This is even more visible in the transversal cuts (Figure 14 right). Robinia fibres show their characteristic fluorescence 
under UV-light, which renders them blue. In places where agglomerates of several fibres occur, there is a high probability that efficient load transfer will be reduced. Consequently, strength properties of the composites with TMP showed reduced strength properties compared to composites with homogeneously distributed wood particles.

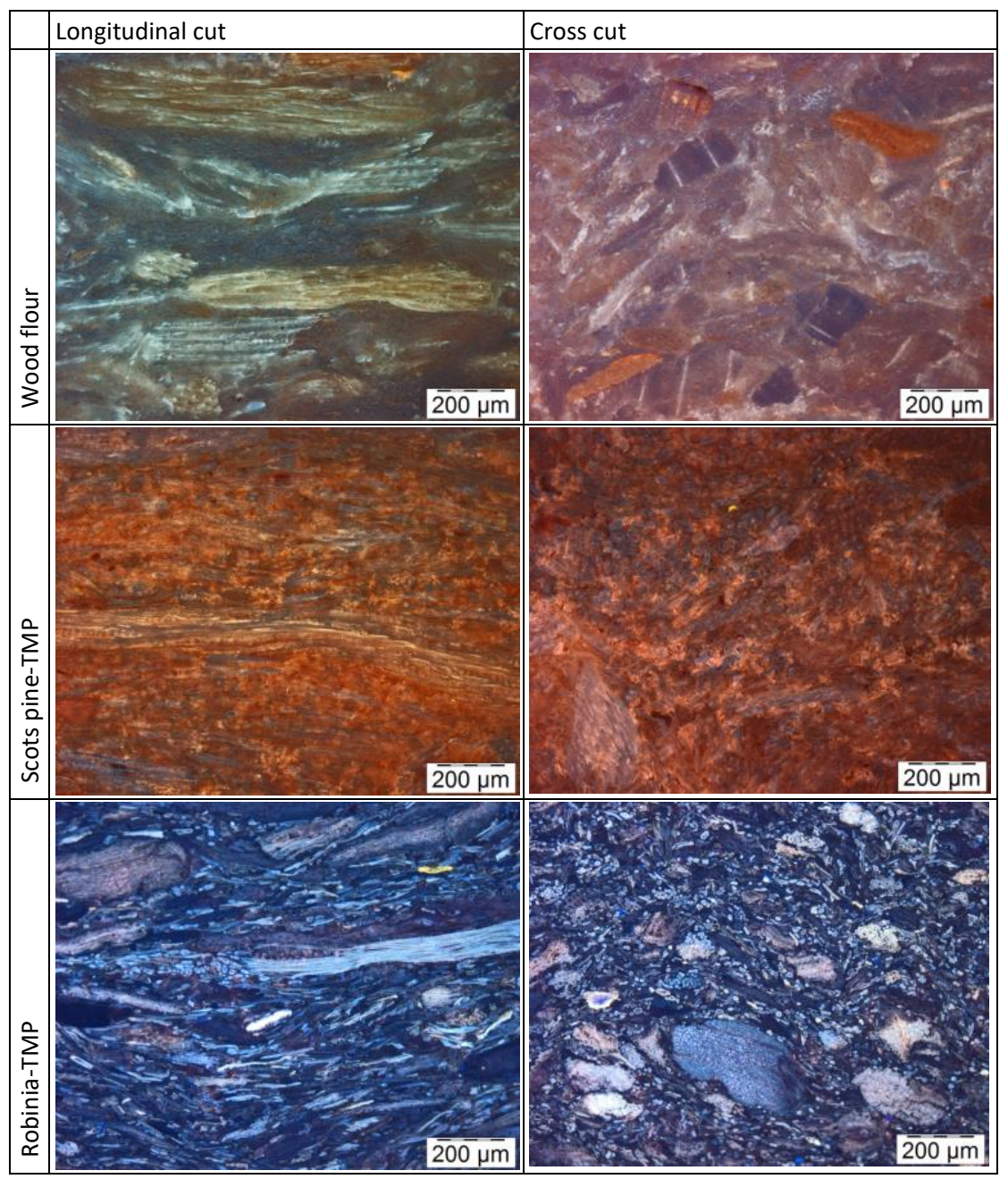

Figure 14. Longitudinal and transversal sections of composites with wood flour (top), Scots pine TMP (centre) and Robinia TMP (bottom) under UV fluorescence. Magnification 100-fold.

Migneault et al. [16] investigated the effects of processing method and fibre size on the structure and properties of WPC. They concluded that increasing fibre L/D ratio had a beneficial effect on mechanical properties but a negative effect on water absorption. Because they did not extract the fibres after processing, L/D ratios after compounding and extrusion were not reported. In previous research, we extracted TMP from the polymer matrix, in this case, after injection-moulding [9]. We found that under the processing conditions, L/D ratios for fibres with increasing length were strongly reduced and that fibres did not perform better compared to wood flour.

\section{Conclusions}

Based on the results in the present study, the following conclusions were drawn:

- Solid versus emulsified MAPP: Under the conditions of this study, pre-treatment of TMP with emulsified, maleated PP after the defibration process did not lead to an improvement in composite performance compared to when maleated PP in solid form was applied during compounding. This was attributed to the chemical nature 
of the emulsifier and the interference of the emulsifier with the MAPP. Possibly, emulsified MAPP works better with increased amounts.

- $\quad$ TMP versus wood flour: The strength properties of WPC made with TMP fibres were lower than those of WPC made with commercial softwood flour, probably due to fibre degradation during compounding and extrusion. In addition, the dispersion of the wood flour in the PP matrix appears to have been better compared to the fibres, and the bonding of the MAPP on TMP fibre surfaces may have been prevented by the presence of lignin on the fibres. The application of a coupling agent which enhances the bonding of a lignin-rich (hydrophobic) fibre surface and polypropylene matrix could be beneficial. Lignin-based coupling agents may be an option and would offer the benefit of a highly bio-based solution.

- $\quad$ TMP based on Robinia versus Scots pine: In terms of flexural, tensile and Charpy impact strength, Robinia TMP showed superior performance compared to Scots pine TMP. This could be due to the higher L/D ratio of Robinia fibres (112) compared to Scots pine tracheids (70-103) since the strength and rigidity of composites increase with increasing $\mathrm{L} / \mathrm{D}$ ratio.

- Higher versus lower temperature during thermomechanical pulping: In the presence of MAPP and with increasing temperature, a decrease in strength properties and an increase in water uptake and swelling were observed. However, in the absence of MAPP, with increasing temperature, strength remained at the same level or was slightly increased, and water uptake was reduced. The results could be partially explained with the chemical composition of the fibre surfaces. If a more hydrophilic fibre surface is generated, better performance of MAPP could be expected. Theoretically, this would be possible if the defibration process was performed at a temperature below the glass transition temperature of lignin, which is approximately $120-140{ }^{\circ} \mathrm{C}$ under the specific conditions during refining, taking into account the moisture of the wood chips, the shear frequency of the refiner, disc geometry, etc. [71]. However, normally, temperatures of $150^{\circ} \mathrm{C}$ and higher are applied in the defibration process because the higher the temperature, the lower the energy required for defibration. At temperatures of $150{ }^{\circ} \mathrm{C}$ and higher, the middle lamella of the fibres, which contains the highest amount of lignin, is plasticized, hence it takes relatively little energy to separate the wood into individual fibres. After the cooling of the fibres, the lignin returns to a glassy state and remains on the fibre surfaces as inert crust. Hence, such fibres are chemically rather inactive. More chemically active fibres can be generated by applying a chemo-thermo-mechanical pulping process.

- Evaluation of coupling agent performance: Some ester links could be detected between TMP and MAPP using ATR-FTIR spectroscopy, which showed that maleic anhydride partially bonded to the fibres; however, some non-activated maleic anhydride remained. XPS results confirmed that softwood flour was more hydrophilic than TMP made from Robinia, as indicated by the higher $\mathrm{O} / \mathrm{C}$ ratio. These surface analysis results can help to explain the mechanical and physical performance of the composites.

Author Contributions: The authors designed and supervised the investigations for this study. The manuscript was written by A.S. and C.S. Both authors have read and agreed to the published version of the manuscript.

Funding: This research was contributed to by funding from the International Association for Technical Issues related to Wood (Internationaler Verein für Technische Holzfragen e.V.), Braunschweig.

Institutional Review Board Statement: Not applicable.

Informed Consent Statement: Not applicable.

Data Availability Statement: Not applicable.

Acknowledgments: The authors thank the International Association for Technical Issues related to Wood (Internationaler Verein für Technische Holzfragen e.V.) for funding and Clariant (Gersthofen) und Byk-Cera (Denekamp, Netherlands) for supplying the coupling agents used in this study. We also 
kindly acknowledge technical support from our colleagues Richard Deetz, Anja Gohla and Heinz Peters, and from Dr. Sven Hartwig, Technical University Braunschweig, for XPS measurements.

Conflicts of Interest: The authors declare no conflict of interest.

\section{References}

1. Warnes, J.M.; Fernyhough, A.; Anderson, C.R.; Lee, B.J.; Witt, M.R.J. Method for Producing Wood Fibre Pellets; Wipo: Geneva, Switzerland, 2006.

2. Warnes, J.; Witt, M.; Anderson, R.; Shar, S. High aspect ratio fibres for reinforcing wood plastic composites. In Proceedings of the Wood-Plastic Composites 2005, Applied Market Information, Vienna, Austria, 5-7 December 2005.

3. Méndez, J.A.; Vilaseca, F.; Pèlach, M.A.; López, J.P.; Barberà, L.; Turon, X.; Gironès, J.; Mutjé, P. Evaluation of the rein-forcing effect of ground wood pulp in the preparation of polypropylene-based composites coupled with maleic anhydride grafted polypropylene. J. Appl. Polym. Sci. 2007, 105, 3588-3596. [CrossRef]

4. Lerche, H.; Benthien, J.T.; Schwarz, K.U.; Ohlmeyer, M. Effects of defibration conditions on mechanical and physical properties of wood fiber/high-density polyethylene composites. J. Wood Chem. Technol. 2013, 34, 98-110. [CrossRef]

5. Stark, N.M.; Rowlands, R.E. Effects of wood fiber characteristics on mechanical properties of wood/polypropylene composites. Wood Fiber Sci. 2003, 35, 167-174

6. Schirp, A.; Stender, J. Properties of extruded wood-plastic composites based on refiner wood fibres (TMP fibres) and hemp fibres. Eur. J. Wood Prod. 2010, 68, 219-231. [CrossRef]

7. Horbens, M.; Pfriem, A.; Ganster, J.; Wagenführ, A. Holzfasern als Verstärkungsfasern in Holz-Polypropylen-Verbundwerkstoffen. Holztechnologie 2012, 53, 21-25. (In German)

8. Thumm, A.; Dickson, A.R. The influence of fibre length and damage on the mechanical performance of polypropylene/wood pulp composites. Compos. Part A Appl. Sci. Manuf. 2013, 46, 45-52. [CrossRef]

9. Schirp, A.; Mannheim, M.; Plinke, B. Influence of refiner fibre quality and fibre modification treatments on properties of injection-moulded beech wood-plastic composites. Compos. Part A Appl. Sci. Manuf. 2014, 61, 245-257. [CrossRef]

10. Klason, C.; Kubát, J.; Strömvall, H.-E. The efficiency of cellulosic fillers in common thermoplastics. Part 1. Filling without processing aids or coupling agents. Int. J. Polym. Mater. 1984, 10, 159-187. [CrossRef]

11. Raj, R.G.; Kokta, B.V.; Maldas, D.; Daneault, C. Use of wood fibers in thermoplastic composites: VI. Isocyanate as a bonding agent for polyethylene-wood fiber composites. Polym. Compos. 1988, 9, 404-411. [CrossRef]

12. Maldas, D.; Kokta, B. Improving adhesion of wood fiber with polystyrene by the chemical treatment of fiber with a coupling agent and the influence on the mechanical properties of composites. J. Adhes. Sci. Technol. 1989, 3, 529-539. [CrossRef]

13. Maldas, D.; Kokta, B.V. Effects of coating treatments on the mechanical behavior of wood-fiber-filled polystyrene composites. I. Use of polyethylene and isocyanate as coating components. J. Appl. Polym. Sci. 1990, 40,917-928. [CrossRef]

14. Beg, M.; Pickering, K. Mechanical performance of Kraft fibre reinforced polypropylene composites: Influence of fibre length, fibre beating and hygrothermal ageing. Compos. Part A Appl. Sci. Manuf. 2008, 39, 1748-1755. [CrossRef]

15. Migneault, S.; Koubaa, A.; Erchiqui, F.; Chaala, A.; Englund, K.; Krause, C.; Wolcott, M. Effect of fiber length on processing and properties of extruded wood-fiber/HDPE composites. J. Appl. Polym. Sci. 2008, 110, 1085-1092. [CrossRef]

16. Migneault, S.; Koubaa, A.; Erchiqui, F.; Chaala, A.; Englund, K.; Wolcott, M.P. Effects of processing method and fiber size on the structure and properties of wood-plastic composites. Compos. Part A Appl. Sci. Manuf. 2009, 40, 80-85. [CrossRef]

17. Renneckar, S.; Zink-Sharp, A.; Glasser, W.G. Fiber surface modification by steam-explosion: Sorption studies with co-refined wood and polyolefins. Wood Fiber Sci. 2006, 38, 427-438.

18. Mertens, O.; Krause, K.C.; Krause, A. Evaluation of wood fiber composites based on a novel simultaneous defibration and compounding process. J. Appl. Polym. Sci. 2018, 135, 45859. [CrossRef]

19. Mertens, O.; Gurr, J.; Krause, A. The utilization of thermomechanical pulp fibers in WPC: A review. J. Appl. Polym. Sci. 2017, 134, 45161. [CrossRef]

20. Nygård, P.; Tanem, B.; Karlsen, T.; Brachet, P.; Leinsvang, B. Extrusion-based wood fibre-PP composites: Wood powder and pelletized wood fibres-A comparative study. Compos. Sci. Technol. 2008, 68, 3418-3424. [CrossRef]

21. Peltola, H.; Pääkkönen, E.; Jetsu, P. Effects of physical pretreatment of wood fibres on fibre morphology and biocomposite properties. Plast. Rubber Compos. 2011, 40, 86-92. [CrossRef]

22. Peltola, H.; Pääkkönen, E.; Jetsu, P.; Heinemann, S. Wood based PLA and PP composites: Effect of fibre type and matrix polymer on fibre morphology, dispersion and composite properties. Compos. Part A Appl. Sci. Manuf. 2014, 61, 13-22. [CrossRef]

23. Solala, I.; Koistinen, A.; Siljander, S.; Vuorinen, J. Composites of high-temperature thermomechanical pulps and polylactic acid. BioResources 2015, 11, 1125-1140. [CrossRef]

24. Filgueira, D.; Holmen, S.; Melbø, J.K.; Moldes, D.; Echtermeyer, A.T.; Chinga-Carrasco, G. Enzymatic-assisted modification of thermomechanical pulp fibers to improve the interfacial adhesion with poly(lactic acid) for 3D Printing. ACS Sustain. Chem. Eng. 2017, 5, 9338-9346. [CrossRef]

25. Guo, Q.; Cheng, B.; Kortschot, M.; Sain, M.; Knudson, R.; Deng, J.; Alemdar, A. Performance of long Canadian natural fibers as reinforcements in polymers. J. Reinf. Plast. Compos. 2010, 29, 3197-3207. [CrossRef]

26. Wolcott, M.P. Wood-plastic composites. In Encyclopedia of Materials: Science and Technology; Buschow, K.H.L., Chan, R., Flemings, M., Ilschner, B., Kramer, E., Mahajan, S., Veyssiere, P., Eds.; Elsevier: Amsterdam, The Netherlands, 2001; pp. $9759-9763$. 
27. Nechwatal, A.; Reußmann, T.; Bohm, S.; Richter, E. The Dependence between the process technologies and the effect of MAH-PPadhesives in natural fibre reinforced thermoplastic composites. Adv. Eng. Mater. 2005, 7, 68-73. [CrossRef]

28. Felix, J.M.; Gatenholm, P. The Nature of Adhesion in Composites of Modified Cellulose Fibers and PP. J. Appl. Polym. Sci. 1991, 42, 609-620. [CrossRef]

29. Bledzki, A.K.; Reihmane, S.; Gassan, J. Thermoplastics reinforced with wood fillers: A literature review. Polym. Technol. Eng. 1998, 37, 451-468. [CrossRef]

30. Woodhams, R.T.; Thomas, G.; Rodgers, D.K. Wood fibers as reinforcing fillers for polyolefins. Polym. Eng. Sci. 1984, $24,1166-1171$. [CrossRef]

31. Dalväg, H.; Klason, C.; Strömvall, H.-E. The efficiency of cellulosic fillers in common thermoplastics. Part II. Filling with processing aids and coupling agents. Int. J. Polym. Mater. 1985, 11, 9-38. [CrossRef]

32. Felix, J.M.; Gatenholm, P.; Schreiber, H.P. Controlled interactions in cellulose-polymer composites. 1: Effect on mechanical properties. Polym. Compos. 1993, 14, 449-457. [CrossRef]

33. Specht, K. Holz- und hanffaserverstärktes Polypropylen in der Spritzgießverarbeitung: Faseraufschluss- und Verbundaufbereitungsverfahren, Haftvermittler, Alterungsverhalten. Ph.D. Thesis, Institut für Werkstofftechnik—Kunststoff- und Recyclingtechnik, University of Kassel, Kassel, Germany, 2007. (In German).

34. Krzysik, A.M.; Youngquist, J.A. Bonding of air-formed wood fibre/polypropylene fibre composites. Int. J. Adhes. Adhes. 1991, 11, 235-240. [CrossRef]

35. Nechwatal, A.; Reussmann, T.; Lützkendorf, R.; Richter, E. What do coupling agents accomplish in practical processes? Kunststoffe 2004, 12, 156-161.

36. Fang, H.; Zhang, Y.; Deng, J.; Rodrigue, D. Effect of fiber treatment on the water absorption and mechanical properties of hemp fiber/polyethylene composites. J. Appl. Polym. Sci. 2013, 127, 942-949. [CrossRef]

37. Lüdemann, G. Die Robinie in den norddeutschen Bundesländern. Forst Holz 2005, 11, 447-449. (In German)

38. Schirp, A.; Weidenmüller, I. Strategies for improving the resistance of wood-plastic composites (WPC) against wood-decay fungi. In Proceedings of the 8th Global WPC and Natural Fibre Composites Congress and Exhibition, Stuttgart, Germany, 22-23 June 2010.

39. Carlborn, K.; Matuana, L.M. Functionalization of wood particles through a reactive extrusion process. J. Appl. Polym. Sci. 2006, 101, 3131-3142. [CrossRef]

40. Gauthier, R.; Joly, C.; Coupas, A.C.; Escoubes, M. Interfaces in polyolefin/cellulosic fiber composites: Chemical coupling, morphology, correlation with adhesion and aging in moisture. Polym. Compos. 1998, 19, 287-300. [CrossRef]

41. Lu, J.Z.; Wu, Q.; McNabb, H.S. Chemical coupling in wood fiber and polymer composites: A review of coupling agents and treatments. Wood Fiber Sci. 2000, 32, 88-104.

42. Kazayawoko, M.; Balatinecz, J.J.; Matuana, L.M. Surface modification and adhesion mechanisms in wood-fiber-polypropylene composites. J. Mater. Sci. 1999, 34, 6189-6199. [CrossRef]

43. Lee, B.; McDonald, A.G.; James, B. Influence of fibre length on the mechanical properties of woodfibre/polypropylene prepreg sheets. Mater. Res. Inn. 2001, 4, 97-103. [CrossRef]

44. Rude, E.; Laborie, M.-P.G. Carbon-13 Cross polarization magic-angle-spinning nuclear magnetic resonance investigation of the interactions between maleic anhydride grafted polypropylene and wood polymers. Appl. Spectrosc. 2008, 62, 563-568. [CrossRef]

45. Miller, N.A.; Stirling, C.D.; van Tilburg, V.S.M. Effects of fibre treatment on fibre/matrix interfacial bonding in Pinus radiata fibre/thermoplastic composites. Polym. Polym. Compos. 1995, 3, 117-127.

46. Roffael, E.; Dix, B.; Schneider, T. Methode zur Erfassung der Benetzung von Holzfasern. Holz Roh Werkst. 2002, 60, 347-348. (In German) [CrossRef]

47. Schneider, T.; Dix, B.; Roffael, E.; Erbreich, M. Zum Einfluss des Holzes sowie des Holzaufschlussverfahrens auf das Benetzungsverhalten von Kiefern- und Fichten-Faserstoffen. Holz Roh Werkst. 2006, 65, 29-33. (In German) [CrossRef]

48. Wagenführ, R. Holzatlas, 4th ed.; Fachbuchverlag: Leipzig, Germany, 1996. (In German)

49. Rowell, R.M. Handbook of Wood Chemistry and Wood Composites; CRC Press: Boca Raton, Florida, USA, 2005.

50. Irvine, G.M. The significance of the glass transition of lignin in thermomechanical pulping. Wood Sci. Technol. 1985, 19, 139-149. [CrossRef]

51. Ayrilmis, N.; Jarusombuti, S.; Fueangvivat, V.; Bauchongkol, P. Effect of thermal-treatment of wood fibres on properties of flat-pressed wood plastic composites. Polym. Degrad. Stab. 2011, 96, 818-822. [CrossRef]

52. Winandy, J.E.; Krzysik, A.M. Thermal degradation of wood fibers during hot-pressing of MDF composites: Part I. Relative effects and benefits of thermal exposure. Wood Fiber Sci. 2007, 39, 450-461.

53. Braun, D. Erkennen von Kunststoffen: Qualitative Kunststoffanalyse mit einfachen Mitteln, 4th ed.; Carl Hanser: München, Germany, 2003. (In German)

54. Kazayawoko, M.; Balatinecz, J.J.; Woodhams, R.T. Diffuse reflectance fourier transform infrared spectra of wood fibers treated with maleated polypropylenes. J. Appl. Polym. Sci. 1997, 66, 1163-1173. [CrossRef]

55. Carlborn, K.; Matuana, L.M. Composite materials manufactured from wood particles modified through a reactive extrusion process. Polym. Compos. 2005, 26, 534-541. [CrossRef]

56. Qui, W.; Zhang, F.; Endo, T.; Hirotsu, T. Isocyanate as a compatibilizing agent on the properties of highly crystalline cellulose/polypropylene composites. J. Mater. Sci. 2005, 40, 3607-3614. 
57. Sjöström, E.; Alén, R. Analytical Methods in Wood Chemistry, Pulping, and Papermaking; Springer: Berlin, Germany, 1999.

58. Sinn, G.; Reiterer, G.S.; Stanzl-Tschegg, S.E. Surface analysis of different wood species using x-ray photoelectron spectroscopy (XPS). J. Mater. Sci. 2001, 36, 4673-4680. [CrossRef]

59. Chtourou, H.; Riedl, B.; Kokta, B.V. Surface characterizations of modified polyethylene pulp and wood pulps fibers using XPS and inverse gas chromatography. J. Adhes. Sci. Technol. 1995, 9, 551-574. [CrossRef]

60. Johansson, L.-S.; Campbell, J.; Koljonen, K.; Stenius, P. Evaluation of surface lignin on cellulose fibers with XPS. Appl. Surf. Sci. 1999, 92-95. [CrossRef]

61. Matuana, L.M.; Kamdem, D.P. Accelerated ultraviolet weathering of PVC/wood-flour composites. Polym. Eng. Sci. 2002, 42, 1657-1666. [CrossRef]

62. Migneault, S.; Koubaa, A.; Perré, P.; Riedl, B. Effects of wood fiber surface chemistry on strength of wood-plastic composites. Appl. Surf. Sci. 2015, 343, 11-18. [CrossRef]

63. Dorris, G.M.; Gray, D.G. The surface analysis of paper and wood fibres by ESCA (electron spectroscopy for chemical analysis). I. Application to cellulose and lignin. Cellul. Chem. Technol. 1978, 12, 9-23.

64. Kamdem, D.P.; Riedl, B.; Adnot, A.; Kaliaguine, S. ESCA spectroscopy of poly(methyl methacrylate) grafted onto wood fibers. J. Appl. Polym. Sci. 1991, 43, 1901-1912. [CrossRef]

65. Pickering, K.L.; Abdalla, A.; Ji, C.; McDonald, A.G.; Franich, R.A. The effect of silane coupling agents on radiata pine fiber for use in thermoplastic matrix composites. Compos. Part A Appl. Sci. Manuf. 2003, 34, 915-926. [CrossRef]

66. Beg, M.; Pickering, K. Fiber pretreatment and its effects on wood fiber reinforced polypropylene composites. Mater. Manuf. Process. 2006, 21, 303-307. [CrossRef]

67. Jayme, G. Mikro-Quellungsmessungen an Zellstoffen. Wochenbl. Pap. 1944, 6, 187-194. (In German)

68. Roffael, E.; Bar, G.; Behn, C.; Dix, B. Einfluss der Aufschlusstemperatur auf die morphologischen Eigenschaften von TMP aus Kiefernholz. Holz Roh Werkst. 2008, 67, 119-120. (In German) [CrossRef]

69. Oksanen, T.; Buchert, J.; Viikari, L. The Role of Hemicelluloses in the hornification of bleached kraft pulps. Holzforschung 1997, 51, 355-360. [CrossRef]

70. Kazayawoko, M.; Balatinecz, J.J.; Woodhams, R.T.; Law, S. Effects of Wood fiber surface chemistry on the mechanical properties of wood fiber-polypropylene composites. Int. J. Polym. Mater. 1997, 37, 237-261. [CrossRef]

71. Schneider, T. Untersuchungen über den Einfluß von Aufschlußbedingungen des Holzes und der Faserstofftrocknung auf die Eigenschaften von mitteldichten Faserplatten (MDF). Ph.D. Thesis, University of Göttingen, Göttingen, Germany, 2000. (In German). 